University of Nebraska - Lincoln

DigitalCommons@University of Nebraska - Lincoln

Nutrition \& Health Sciences Dissertations \& Theses

Nutrition and Health Sciences, Department of

4-2012

\title{
ASSESSMENT OF NUTRITION KNOWLEDGE AND SELF-EFFICACY OF NCAA ATHLETES
}

Melissa M. Wallinga

University of Nebraska-Lincoln, melissa.wallinga@gmail.com

Follow this and additional works at: https://digitalcommons.unl.edu/nutritiondiss

Part of the Dietetics and Clinical Nutrition Commons

Wallinga, Melissa M., "ASSESSMENT OF NUTRITION KNOWLEDGE AND SELF-EFFICACY OF NCAA ATHLETES" (2012). Nutrition \& Health Sciences Dissertations \& Theses. 31.

https://digitalcommons.unl.edu/nutritiondiss/31

This Article is brought to you for free and open access by the Nutrition and Health Sciences, Department of at DigitalCommons@University of Nebraska - Lincoln. It has been accepted for inclusion in Nutrition \& Health Sciences Dissertations \& Theses by an authorized administrator of DigitalCommons@University of Nebraska - Lincoln. 


\title{
ASSESSMENT OF NUTRITION KNOWLEDGE AND SELF-EFFICACY OF NCAA ATHLETES
}

by

Melissa M. Wallinga

A THESIS Presented to the

\author{
Faculty of \\ The Graduate College at the University of Nebraska \\ In Partial Fulfillment of Requirements \\ For the Degree of Master of Science
}

Major: Nutrition and Health Sciences

Under the Supervision of Professor Wanda M. Koszewski

Lincoln, NE

April, 2012 


\title{
ASSESSMENT OF THE NUTRIENT INTAKE AND KNOWLEDGE OF NCAA ATHLETES
}

\author{
Melissa M. Wallinga, MS \\ University of Nebraska, 2012
}

Advisor: Wanda M. Koszewski

BACKGROUND Little data has been collected on the nutrition knowledge and self efficacy of NCAA Athletes, and if Sports Nutrition Departments at Universities do positively affect the nutrition knowledge and self-efficacy of athletes.

OBJECTIVES To determine and compare differences in nutrition knowledge and self-efficacy of athletes at two NCAA Division I Universities, one with a Sports Nutrition Department, and one without.

SETTING Participants completed a survey in person at their respective University.

PARTICIPANTS Male and female student athletes ( $\mathrm{n}=327)$ from two Division I Universities, participating in men's football, men’s wrestling, women's soccer, or women's swimming/diving.

RESULTS Approximately $42 \%$ of the participants ( $\mathrm{n}=137$ ) were from School A, the University without a full-time Sports Registered Dietitian (RD), and approximately 58\% ( $\mathrm{n}=190$ ) were from School B, the University with a full-time Sports RD. In general, a significantly higher number of athletes from school B received their nutrition information 
from a Sports RD $(\mathrm{p}<0.05)$. Athletes from school A received most of their nutrition information from a strength and conditioning coach (28\%), family (23\%), and the internet (26\%). Athletes from school B identified their main sources of nutrition information as strength and conditioning coaches (43\%), teammates (26\%), the internet (28\%), and a Registered Dietitian (24\%). A significant amount more athletes from school B identified that they actively seek out nutrition information, were aware of how many calories they should consume, and identified having a Sports Nutritionist at their University benefiting them as an athlete $(\mathrm{p}<0.05)$. More significant differences were found regarding sources of nutrition information and counseling and nutrition knowledge among football athletes than among the other three sports $(\mathrm{p}<0.05)$.

CONCLUSIONS AND IMPLICATIONS The athletes from the University with the full-time Sports RD more often sought out nutrition information, saw more importance in seeking out nutrition information, were more knowledgeable about nutrition, and were more confident in making certain nutrition decisions. Each Division I University should have, on campus, a full time Sports Registered Dietitian. 


\section{ACKNOWLEDGEMENTS}

I would first like to thank my Lord and Savior Jesus Christ for the many blessings I have been given. Without Him none of this would be possible; He has guided every step I've taken, every relationship I've formed, and every decision I've made. I have seen his hand in every opportunity He has given me. I stand in amazement of all He has done and continues to do in my life.

I would also like to thank Dr. Wanda Koszewski for every opportunity you have given me, especially the chance to be a part of this research and to get to learn about something I am so passionate about. I cannot thank you enough for your patience, encouragement, love, and support. You were there to guide me and encourage me to have confidence in my abilities and my talents. Also, thank you to Dr. Shinya Takahashi and Dr. Candace Kohnke for serving on my thesis committee and providing your guidance, expertise, and support.

I would like to thank my amazing husband Kent for his continuous love, support, encouragement, and listening ear. I seriously could not have done this without you and everything you did to make this experience positive and as smooth as possible. Also, thank you to my family, especially my parents, John and Terri Hisel, who prayed for me, loved me, and supported me, reminding me every day that I am blessed and can do anything I set my mind to.

Thank you also to everyone who worked extremely hard to make this research a success, including the participants. I would also like to thank Alyssa Vierregger, Emily Estes, and Garrett Serd who were there from the beginning to encourage me and were willing to do anything to help this research be successful. Your friendship is appreciated more than you know. I'd especially like to thank Coach Tim Socha and Boise State University and Josh Hingst and the University of Nebraska, Lincoln for your participation in this study. Thank you! 


\section{TABLE OF CONTENTS}

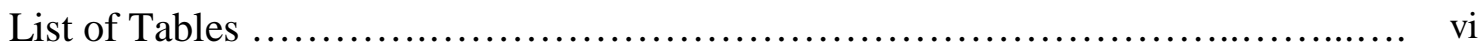

List of Appendices ................................................... vii

Chapter I. Introduction..................................................... 8

References for Introduction............................................ 21

Chapter II. Manuscript............................................................................... 23

Purpose................................................................. 24

Hypothesis.............................................................. 24

Objectives............................................................... 24

Methodology ........................................................ 25

Subjects....................................................... 25

Data Collection Tools................................................ 26

$\begin{array}{lr}\text { Data Collection Procedure } & 27\end{array}$

Data Analysis...................................................... 28

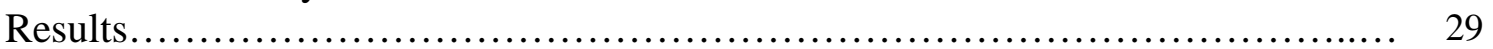

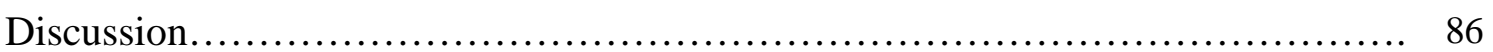

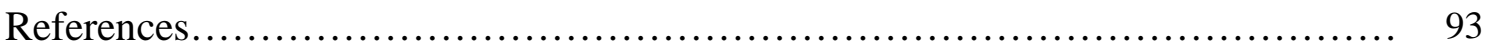

Chapter III. Conclusions................................................. 94

Conclusion.................................................................. 94

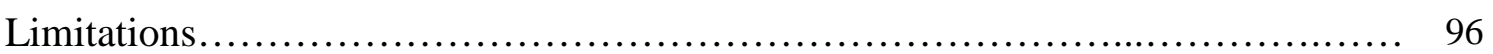

Implications for Further Research......................................... 97

Appendices................................................................ 99 


\section{LIST OF TABLES}

1. Demographic information of all college athletes in the study

2. Demographic information of men's college football athletes

3. Demographic information of men's college wrestling athletes

4. Demographic information of women's college soccer athletes

5. Demographic information of women’s college swimming/diving athletes

6. Comparing sources of nutrition counseling and information of all athletes in the study

7. Comparing sources of nutrition counseling and information of men's football athletes

8. Comparing sources of nutrition counseling and information of men's wrestling athletes

9. Comparing sources of nutrition counseling and information of women's soccer athletes

10. Comparing sources of nutrition counseling and information of women's swimming/diving athletes

11. Comparing nutrition knowledge of all athletes in the study

12. Comparing nutrition knowledge of men's football athletes

13. Comparing nutrition knowledge of men's wrestling athletes

14. Comparing nutrition knowledge of women's soccer athletes

15. Comparing nutrition knowledge of women's swimming/diving athletes

16. Comparing self-efficacy of all athletes in the study

17. Comparing self-efficacy of men's football athletes

18. Comparing self-efficacy of men's wrestling athletes

19. Comparing self-efficacy of women's soccer athletes

20. Comparing self-efficacy of women's swimming/diving athletes 


\section{LIST OF APPENDICES}

A-1 Institutional Board Letter of Approval

A-2 University of Nebraska-Lincoln, Letter of Approval

A-3 Boise State University, Letter of Approval

A-4 Informed Consent Form

A-5 Athlete Survey

A-6 Script for initial recruitment meeting 
CHAPTER I

INTRODUCTION

\section{Nutrition Recommendations for College Athletes:}

A joint position statement released by the American College of Sports Medicine, the American Dietetic Association, and Dietitians of Canada $^{1}$ states that optimal nutrition enhances athletic performance and exercise recovery. It is a priority that athletes meet their nutrition needs as nutrition promotes optimal athletic performance. When an athlete's nutrition needs are met, they are better able to maintain a healthy body weight and body composition. ${ }^{1-4}$ Both of these components are an important part of maximizing performance; nutritional status can be the difference between winning and losing. ${ }^{1-4}$

The American College of Sports Medicine, the American Dietetic Association, and Dietitians of Canada ${ }^{1}$ have put forth carbohydrate, fat, and protein recommendations for athletes. It is important to note that the following recommendations should be specialized for each athlete and this can be done by a Sports Registered Dietitian. ${ }^{1}$ The recommendations for athletes follow fairly closely with the Dietary Guidelines for Americans and should be based on Dietary Reference Intakes and Recommended Daily Allowances. ${ }^{1,5}$ Maintaining a balanced and varied diet is also vital for an athlete; they should follow MyPyramid (MyPlate) recommendations and be sure to consume enough fruits and vegetables along with meats and grains. ${ }^{3}$

The International Society of Sports Nutrition ${ }^{6}$ suggests the first aspect of maximizing performance and training through nutrition is to be sure athletes are consuming enough calories to offset the amount of calories they are expending on a daily 
basis. Total energy intake is an important aspect of nutrition for athletes, but unfortunately this concept is often misunderstood. Many athletes who are involved in sports where being extremely lean and "cutting weight" is important struggle with meeting their total energy needs. They also don't realize that this can actually be a detriment to their performance and health. Athletes participating in intense training, 2-3 hours per day, or high-volume intense training, 3-6 hours per day, like most college athletes do, have significantly increased calorie needs. ${ }^{6}$ Hinton et al. ${ }^{2}$ give recommended intakes for athletes based on the Recommended Dietary Allowances and Dietary Guidelines. ${ }^{2}$ For active males, an estimated $2900 \mathrm{kcal}$ (40 kcal/kg body weight) are needed each day to stay in energy balance; for females approximately 2200 kcal (38 $\mathrm{kcal} / \mathrm{kg}$ body weight) are needed.

Carbohydrate is needed to maintain glycogen stores for the athlete. ${ }^{2,6}$ Because most college athletes, specifically at Division I Universities, are participating in 2-6 hours of training per day, their bodies need more carbohydrate than the average individual, or even individuals in a general fitness program. ${ }^{6}$ It is recommended an athlete consume 6 to $10 \mathrm{~g} \cdot \mathrm{kg}$ body weight. ${ }^{1-2,6}$ Based on these and total energy recommendations $65 \%$ of an athlete's diet should consist of carbohydrates. ${ }^{2}$ Carbohydrate is often the first macronutrient which is cut from an athlete's diet when they are trying to lose weight. This can have detrimental effects on health and performance and should be avoided; the previous recommendations should be followed in most situations.

Protein is needed for gains in lean muscle mass and in some specific cases, according to the American College of Sports Medicine and Hinton et $\mathrm{al}^{1-2}$, it is needed in slightly higher amounts for the athlete simply because they are more active. If an athlete 
does not consume enough protein, they will be in negative nitrogen balance, which can increase the catabolism of protein, slowing recovery. ${ }^{6}$ It is recommended an athlete consume $1.2-1.7 \mathrm{~g} \cdot \mathrm{kg}$ body weight of protein, which should be $15 \%$ of total energy intake. ${ }^{1-2,6}$ There are athletes such as swimmers, gymnasts, wrestlers, and boxers, which are more susceptible to protein malnutrition, and it is important to have an educator available to these athletes in order to prevent this. ${ }^{6}$ Many athletes are bombarded with information regarding protein supplementation and they are not sure what to believe and follow. The International Society of Sports Nutrition ${ }^{6}$ recommends obtaining protein from whole foods before supplementation is explored. Guidance is important for an athlete, especially regarding protein, so they are first meeting their protein needs through food, not consuming it in excess amounts, and so they are consuming enough to meet the demands of increasing muscle mass.

Fat is a macronutrient which is largely over-consumed in America, even in the athletic population. ${ }^{2}$ Although excess fat can cause weight gain, fat is an important part of an athlete's diet as it is a source of energy, fat-soluble vitamins, and essential fatty acids. ${ }^{1,6-7}$ As Zello ${ }^{7}$ describes, it also plays an important role in assisting in the absorption of vitamins and the development of tissues. It is recommended that fats are $20-35 \%$ of total energy intake and that $7 \%$ of fat intake should be saturated fats, $10 \%$ should be polyunsaturated fats, and $10-13 \%$ should be monounsaturated fats. ${ }^{5-6}$ Some athletes, who need to lose adipose weight in order for performance gains have lower fat recommendations, but it is important for an athlete to be properly educated on these recommendations before they begin the regiment. ${ }^{6}$ It is important these recommendations are met for the reasons previously stated but also as Zello ${ }^{7}$ points out, in order to meet the 
recommended amounts of essential fatty acids, linoleic acid, alpha linolenic acid, eicosapentaenoic acid, and docosahexanois acid. It is important athletes follow these recommendations in order to maximize their health and performance as performance can decrease if intakes are too high or too low. ${ }^{7}$

Macronutrients are most often the focus of diets but micronutrients, vitamins and minerals, are also an important aspect of an athlete's diet. When energy intake is sufficient it is not likely that micronutrient inadequacies will be present, but in cases of low energy intake, such as are common in some athletes, micronutrient inadequacies can be found. ${ }^{8}$ Vitamins are important for the regulation of metabolic processes, synthesis of energy, proper function of neurological processes, and prevention of the destruction of cells in the body. ${ }^{1,6}$ Minerals play an important role in the structure for tissues, are an important component of enzymes and hormones, and regulate metabolic and neural processes. ${ }^{1,6}$ Micronutrients in general are vital in the repair of muscle tissue during recovery, which is especially important for athletes. ${ }^{1,6}$ When vitamin and mineral intake is inadequate, not only will effectiveness of recovery be reduced, but exercise capacity may also be reduced, making the athlete less effective in both practice and game situations. ${ }^{6}$ Although they are not often focused on, vitamins and minerals can be turned over much quicker in an athlete and therefore are sometimes needed in greater amounts. ${ }^{1}$ Certain athletes, especially those involved in weight-loss practices or diet restrictions, because of low energy intake, are more susceptible to vitamin and mineral loss and their diets should be monitored. It is suggested that these types of athletes will benefit from a daily multi-vitamin and mineral supplement. ${ }^{1,6,8}$ In general, this benefit is not to performance, but to overall health of the athlete, however, in some severely deficient 
athletes, it is thought that mineral supplementation may enhance exercise capacity. ${ }^{6,8}$ According to Volpe ${ }^{8}$, for athletes consuming low-energy diets, levels of iron, calcium, magnesium, zinc, and Vitamin $\mathrm{B}_{12}$ can be of concern and focus on consuming foods containing these nutrients is very important.

With these specific macro-and micronutrient recommendations, also come specific timing recommendations. Nutrient timing has been identified as a very important aspect of proper nutrition among athletes, playing a role in optimizing performance, training adaptations, and preventing overtraining. ${ }^{6,9}$ The general recommendations, as made by the International Society of Sports Nutrition ${ }^{6,9}$ include; pre-exercise meals 4-6 hours before exercise, a light snack (high in protein and carbohydrate and low in fat) 3060 minutes prior to exercise, snacks high in carbohydrates every 15-20 minutes during performance lasting longer than an hour (usually a carbohydrate/electrolyte solution), and a snack high in carbohydrate and protein within 30 minutes after exercise. If proper nutrient timing strategies are identified and followed by athletes, glycogen resynthesis may be accelerated and muscle recovery may be quicker. 6,9

Hydration is another important part of optimal performance. Fluid intake is vital as optimal hydration reduces the risk of heat injuries that are potentially life- threatening. ${ }^{1,6}$ When exercising, evaporation of sweat is the body's way of regulating core temperature. ${ }^{10}$ When an athlete sweats they lose valuable fluids, which include electrolytes that are needed in order to maintain performance. ${ }^{10}$ Sweat losses greater than 2\% can equate to decreased exercise performance. ${ }^{6}$ Athletes should properly hydrate before, during, and after exercise in order for the body’s temperature to remain regulated and to avoid heat illness. ${ }^{6,10}$ Athletes need to be educated on proper hydration methods in 
order to maintain electrolyte balance and replenish fluids lost through sweat. Proper hydration can also help to reduce fatigue during athletic performance. ${ }^{1}$ While water is the most important means of hydration for an athlete, another aspect of fluid intake is knowing when to consume sports drinks such as Gatorade or Powerade. ${ }^{6}$ The general recommendation is to consume sports drinks when exercise or performance lasts longer than 60 minutes, and water for performance lasting less than 60 minutes. ${ }^{6}$ Sports drinks, with a 6-8\% carbohydrate solution (608 grams per $100 \mathrm{~mL}$ ) are also a good source of carbohydrates for the body during prolonged exercise. ${ }^{6,11}$ The timing and amount recommendations for athletes prior, during, and after exercise are as follows: Two to three hours prior to exercise, the National Athletic Trainer's Association ${ }^{10}$ recommends an athlete consume 17 to 20 fluid ounces of water or a sports drink and 7 to 10 fluid ounces of water or a sports drink 10 to 20 minutes before exercise. During exercise, an athlete should consume 7 to 10 fluid ounces every 10 to 20 minutes; following recommendations on consuming sports drink when exercise lasts longer than 60 minutes. ${ }^{10-11}$ The goal of post-exercise hydration should be to replace fluid losses within two hours of the end of competition. ${ }^{10}$ The athlete should consume sports drinks during this time in order to replace fluid, replenish glycogen stores with carbohydrates, and speed up rehydration through electrolytes. ${ }^{10}$ It is important for athletes to be made aware of the importance of proper hydration and also that they are provided with the necessary fluids before, during, and after physical activity. 


\section{Nutrient intake behavior of college athletes}

According to Morse and Driskell ${ }^{12}$, athletes are largely unaware of their nutrition needs, the importance of meeting these needs, and also how to meet these needs. This is a problem which needs to be addressed; however there is not a lot of data on the intake behavior of athletes. ${ }^{13}$ A few studies have been completed, most of them many years ago, and are too far removed to gain significant data from. It is also difficult to directly relate them to athletes today as the whole face of athletics, especially at the NCAA Division I level, has dramatically changed. According to one recent study, done by Hinton and colleagues $^{2}$, diets of athletes are generally low in carbohydrate and protein and high in fat when compared to recommendations. It was also found that males have a higher intake of fat than females and that they also consume less than recommended total energy intake. ${ }^{2}$ The same study found average nutrient intakes of athletes met or surpassed the RDA's for every nutrient except Vitamin E and magnesium. ${ }^{2}$ But when using the Estimated Average Requirement (EAR) cut-point method, which estimates the proportion of individuals in the group which have inadequate intakes, a large proportion of the athletes were also lacking in intakes of folate and zinc.,14

There are other factors, apart from knowledge, which affect the nutrient intake behaviors of college athletes. One study done with NCAA DII football players identified time, specifically academic and athletic schedules, and finances as the main factors affecting their nutrient intake behaviors. ${ }^{15}$ The football players in this study discussed often buying based on cost rather than on nutrient content. ${ }^{15}$ Based on their findings, the researchers suggested athletes would benefit from education on what they should be eating and also how to make this fit into busy schedule and tight finances. ${ }^{15}$ This data 
suggests that there are some significant issues regarding athlete's intake behaviors and there is room for improvement and also intervention. Additional studies must be done to further the understanding of nutrient intake behaviors of college athletes.

\section{Nutrition knowledge of college athletes}

Adequate nutrition knowledge likely leads to better nutrient intake decisions, and can ultimately assist in optimizing athletic performance. ${ }^{4}$ The more an athlete knows, the better informed decisions they can make, and the more ownership they have over their diet and consequently athletic performance. It is important to keep athletes informed and help them understand how nutrition plays a role in their performance and how to make the most of their intake behaviors.

Diets of athletes are less than optimal in certain areas such as low energy, carbohydrate, and micronutrient intake and high fat intake, often due to a lack of knowledge and they often do not understand the benefits of maintaining a healthy diet. ${ }^{2,16}$ The problem often lies in where athletes are receiving their nutrition knowledge. Some studies have found that the knowledge of female athletes is most problematic, but the knowledge of male athletes is also suspect. ${ }^{16}$ Morse and Driskell ${ }^{12}$ found that male and female college students obtain most of their nutrition knowledge from classes, family members, magazines and newspapers, and friends. It is interesting to note that the one of the places college students get their nutrition information from the least is Registered Dietitians (as well as “other” such as the internet and other health professionals). ${ }^{12} \mathrm{~A}$ study specifically done with college football players found that the training room was the primary place athletes were receiving their knowledge, $49.6 \%$ of athletes reported getting 
their information from strength and conditioning coaches or athletic trainers as opposed to the $5.6 \%$ which received their knowledge from a nutritionist. ${ }^{3}$ The same study also found very small percentages of the athletes could properly identify the correct carbohydrate, protein, and fat intake. ${ }^{3}$ Casa and colleagues ${ }^{3}$ completed a study in order to examine the effectiveness of nutrition knowledge interventions and found that athletes who participated in education sessions showed an increase in nutrition knowledge and reported greater self efficacy during the post-tests. It is apparent from the very few studies that have been done that intervention is beneficial and is needed in the area of nutrition knowledge of athletes.

\section{Importance of Sports Nutrition Departments}

Sports Nutrition departments at Universities are becoming more prevalent and proving to be an important aspect of an athlete's experience and performance at the college level. Part of the success of Sports Nutrition programs has been in assisting athletes in losing or gaining weight, when appropriate, in the correct way. Although there have not been studies specifically examining the effects of a Sports Nutrition program on college athletes, studies examining nutrient intake and nutrition knowledge have identified the importance of these types of programs. ${ }^{1-4,8,13,17}$ While nutrition and hydration are pivotal to athletic performance, there is a relatively high nutritional risk among college athletes. ${ }^{4}$ It is important for a Sports Dietitian to be available to assist athletes in setting nutritional and performance goals which focus on consuming a balanced and varied diet in order to improve health and performance. ${ }^{8}$ 
Regarding nutrition knowledge, Cole et $\mathrm{al}^{3}$, states that implementing a program which involves nutrition education for athletes may help reduce the amount of misinformation athletes are receiving. Other authors suggest collegiate athletic association's should consider using qualified Sports Dietitians to counsel athletes and provide the athletes with information that is correct, sound, and beneficial. ${ }^{13}$ Jonnalagadda et al. ${ }^{13}$ also suggest athletes would benefit from an individual who can assist them in understanding fluid intake, the role of nutrients in the body, muscle growth and development, and promote healthy dietary behaviors.

Because unsound dietary practices can be detrimental to an athlete’s performance and overall health, it is vital they receive their counseling and information from a professional who is well educated in the field of Sports Nutrition. ${ }^{18-20}$ Training Tables are another important aspect of Sports Nutrition Departments which can assist athletes in making proper nutrition decision. These are dining centers where athletes can go to eat. In general, these centers have educational pieces, designed by the Sports Dietitian and coinciding with the individual counseling pieces, so the athletes can make more informed decisions about what options they are choosing. Like many other aspects of Sports Nutrition programs, there has not been a vast amount of research done on Training Tables, and it is important to understand how these specialized dining centers make a difference in the diets of athletes at Universities where they do exist. Aside from being a detriment to athletic performance, there are many illnesses such as heat illness, rhabdomyolysis, and illnesses associated with inadequate energy intake, which athletes are more likely to struggle with when they are not properly educated in nutrition. As described by Hobart and Smucker ${ }^{19}$ and Coris et al $^{18}$ access to a Sports Dietitian who can 
assist athletes in preventing and monitoring risk factors associated with these types of illnesses is vital. If they have access to this type of professional, athletes are less likely to compromise their training or performance. ${ }^{13,18}$

Researchers suggest that optimizing hydration status is a major part of improving athletic performance. ${ }^{18}$ In addition to improved performance, without proper hydration guidance and practices athletes will be more susceptible to heat illness. ${ }^{18}$ There are many types of heat illness, with heat stroke being the most severe and a medical emergency. ${ }^{18}$ Heat production is significantly greater during exercise and without proper adjustments, can raise core body temperature very quickly. ${ }^{18}$ Risk factor awareness and early detection of the illness are of upmost importance concerning heat illness. ${ }^{18}$ Athletes need to be aware of the risk factors for the various types of heat illness such as dehydration, lack of acclimation to the extreme heat or humidity, and sleep deprivation. ${ }^{18}$ One study examined hydration status in college football players during twice-a-day practices and found that athletes did lose weight from fluid loss during these practices. ${ }^{21}$ Encouragingly, the study also found that athletes were able to gain weight back overnight by replacing fluid. ${ }^{21}$ As is evident from the studies examined and as previously described, it is vital that athletes follow proper pre-, during, and post-exercise hydration protocols in order to decrease the risk of heat illness. ${ }^{18,21}$ A nutrition professional is someone who would be able to properly educate athletes on the risk factors, prevention of heat illness, and proper hydration protocols.

Rhabdomyolysis is another condition which is linked to preventable causes that can be better controlled if athletes are under the care of a sports nutrition professional. Rhabdomyolysis is a severe breakdown of skeletal muscle and can be caused by 
strenuous and overexerting exercise. ${ }^{22}$ This condition can have serious ramifications such as kidney failure and compartment syndrome. ${ }^{22}$ This condition has recently been seen in an increasing number of athletes, and even in athletes participating in well-known athletic departments. The largest cause of this condition is insufficient hydration status. ${ }^{22}$ If athletes are better educated and under close watch of a Sports Dietitian, it is more likely that Rhabdomyolysis and other similar conditions will be prevented.

Another serious type of illness found commonly among athletes, specifically female athletes, is illness associated with inadequate energy intake and disordered eating patterns. The female athlete triad, as defined by Hobart and Smucker ${ }^{19}$ is "a combination of three interrelated conditions that are associated with athletic training: disordered eating, amenorrhea, and osteoporosis.” Quatromoni ${ }^{4}$, states that approximately one-third or more of female college athletes have a clinical eating disorder, which includes anorexia nervosa and bulimia nervosa. These clinical eating disorders and other disordered eating patterns can often lead to amenorrhea, or the absence of menstruation, which can have many detrimental effects. ${ }^{19}$ Amenorrhea can remove estrogen's restraint on bone absorption and can suppress the hormones which promote bone formation. ${ }^{19-20}$ When bone mineral formation is suppressed for a prolonged period of time, the occurrence of stress fractures becomes more likely. ${ }^{20,23}$ These fractures can occur anywhere and become especially dangerous and serious when found in vertebral bone. ${ }^{23}$ A study examining lumbar spine mineral content in runners with amenorrhea found that mineral content was below normal and below the levels of runners in the same study that did not have amenorrhea. ${ }^{24}$ Not only is this a serious issue for an athlete when they are at competition age, but can follow them through the remainder of their life as a loss in bone 
mineral density may not be fully reversible and the risk of osteoporosis becomes much higher. $^{20,23}$ Early detection of disordered eating is crucial because it can be preventable if it is identified before the behaviors become too serious. ${ }^{4}$ Nutritional counseling and education is an essential part of prevention of the female athlete triad and the symptoms associated with the disease, because low energy intake is the primary cause of the disease. ${ }^{19-20}$ A Sports Dietitian is also someone who can screen athletes for the disease, and is someone who should be on the treatment team for an athlete who has been diagnosed. $^{4,20}$

Because there are so many inadequacies and problems in the diets of athletes, which can often lead to the aforementioned illnesses and diseases, nutrition programs implemented in Universities which currently do not have one could prove to be extremely beneficial. The American College of Sports Medicine (ACSM), the American Dietetic Association (ADA), and Dietitians of Canada (DC) ${ }^{1}$ discuss the importance of Sports Dietitians and their responsibilities. Some of these responsibilities include, but are not limited to, conducting nutrition assessments and consultations; educating athletes on food selection and purchasing; assisting in the operation of Training Tables; developing personalized nutrition and hydration plans for each athlete; and giving advice on dietary supplements, ergogenic aids, and sports drinks, bars, and gels. ${ }^{1}$ When following the recommendations set by these professional organizations, Sports Dietitians can be a vital aspect of an athlete’s optimal performance and overall health. 


\section{REFERENCES FOR INTRODUCTION}

1. American College of Sports Medicine (ACSM), the American Dietetic Association (ADA), and Dietitians of Canada (DC). Medicine \& Science in Sports \& Exercise. 2009; 41(3): 709-731.

2. Hinton, PS, Sanford, TC, Davidson, M, Yakushko, OF, Beck, NC. Nutrient intakes and dietary behaviors of male and female collegiate athletes. International Journal of Sport Nutrition and Exercise Metabolism. 2004; 14(4), 389-405.

3. Cole, CR, Salvaterra, GF, Davis JE, et al. Evaluation of dietary practices of national collegiate athletic association division I football players. J. Strength Cond. Res. 2005; 19(3): 490-494.

4. Quatromoni, PA. Clinical observations from nutrition services in college athletics. Journal of the American Dietetic Association. 2008; 108: 689-694.

5. U.S. Department of Agriculture, U.S. Department of Health and Human Services. Dietary Guidelines for Americans 2010; 7.

6. Kreider, RB, Wilborn, CD, Taylor, L, et al. ISSN exercise \& sport nutrition review: research and recommendations. Journal of the International Society of Sports Nutrition. 2010; 7(7): 1-43.

7. Zello, GA. Dietary reference intakes for the macronutrients and energy: considerations for physical activity. Applied Physiology Nutrition Metabolism. 2006; 31: 74-79.

8. Volpe, SL. Micronutrient requirements for athletes. Clinics in Sports Medicine. 2007; 26: $119-130$.

9. Kerksick, C, Harvey, T, Stout, J, et al. International Society of Sports Nutrition position stand: Nutrient timing. Journal of the International Society of Sports Nutrition. 2008; 5: 17-28.

10. Casa, DJ, Armstrong, LE, Hillman, SK, et al. National athletic trainer's association position statement: fluid replacement for athletes. Journal of Athletic Training. 2000; 35(2): 212-224.

11. Burke, LM. Fueling Strategies to optimize performance: training high or training low? Scandinavian Journal of Medicine and Science in Sports. 2010; 20(2): 4858.

12. Morse, KL, Driskell, JA. Observed sex differences in fast-food consumption and nutrition self-assessments and beliefs of college students. Nutrition Research Journal. 2009; 29: 173-179.

13. Jonnalagadda, SS, Rosenbloom, CA, Skinner, R. Dietary practices, attitudes, and physiological status of collegiate freshman football players. J. Strength Cond. Res. 2001; 15(4): 507-513. 
14. Institute of Medicine. Dietary reference intakes: applications in dietary assessment. Washington D.C.: National Academy Press. 2001.

15. Long, D, Perry, C, Unruh, SA., Lewis, N, Stanek-Krogstrand, K. Personal food systems of male collegiate football players: a grounded theory investigation. Journal of Athletic Training. 2011; 46(6): 688-695.

16. Abood, DA, Black, DR, \& Birnbaum, RD. Nutrition education intervention for college female athletes. Journal of Nutrition Education and Behavior. 2004; 36: 135-139.

17. Anderson, D. The impact of feedback on dietary intake and body composition of college women volleyball players over a competitive season. J. Strength Cond. Res. 2010; 24(8): 2220-2226.

18. Coris, EE, Ramirez, AM, Van Durme, DJ. Heat illness in athletes: the dangerous combination of heat, humidity, and exercise. Sports Medicine. 2004; 34(1): 9-16.

19. Hobart, JA, Smucker, DR. The female athlete triad. American family Physician. 2000; 61: 3357-3364, 3367.

20. Nattiv, A, Loucks, AB, Manore, MM, Sanborn, CF, Sundgot-Borgen, J, Warren, MP. The female athlete triad. Medicine \& Science in Sports \&Exercise. 2007; 39(10): 1867- 1882.

21. Fowkes Godek, S, Godek, JJ, \& Bartolozzi, AR. Hydration status in college football players during consecutive days of twice-a-day preseason practices. The American Journal of Sports Medicine. 2005; 33(6): 843-851.

22. Sayers, SP, \& Clarkson, PM. Exercise-induced rhabdomyolysis. Current Sports Medicine Reports. 2002; 1(2): 59-60.

23. Davies, MC, Hall, ML, Jacobs HS. Bone mineral loss in young women with amenorrhea. British Medical Journal. 1990; 301(6755): 790-793.

24. Lindberg, JS, Fears, WB, Hunt, MM, Powell, MR, Boll, D, Wade, CE. Exerciseinduced amenorrhea and bone density. Annals of Internal Medicine. 1984; 101(5): 647-648. 


\section{CHAPTER II}

\section{MANUSCRIPT}

The manuscript will be submitted to the Journal of the Academy of Nutrition and Dietetics as a descriptive research article. The letters of approval from the IRB and the participating Universities are shown in Appendices 1-3. The informed consent form is provided in Appendix 4. The athlete survey is found in Appendix 5. 


\section{PURPOSE}

The purpose of this study was to collect nutrition knowledge and self-efficacy data from athletes at two NCAA Division I Universities to examine differences of the athletes who have access to a nutrition program and those who do not. Results from this study helped to reveal the need for interventions in certain areas of athlete's nutrition knowledge and self-efficacy and also the need for a Sports Nutrition program, including a full-time Registered Dietitian, at all Division I Universities.

\section{HYPOTHESIS:}

The researcher hypothesized that athletes from school A would be less educated regarding nutrition and less confident in making certain nutrition decisions than athletes from school B.

\section{OBJECTIVES}

1. To assess deficits in the nutrition knowledge of NCAA Division I athletes participating in men’s football, men’s wrestling, women’s soccer, and women's swimming and diving at two NCAA Division I Universities.

2. To identify general trends in self-efficacy of NCAA Division I athletes participating in men's football, men’s wrestling, women’s soccer, and women’s swimming and diving at two NCAA Division I Universities.

3. To identify differences in nutrition knowledge and self-efficacy of athletes at a University with a nutrition program and of athletes at a University without a nutrition program 


\section{METHODOLOGY}

The goal of this study was to assess the nutrition knowledge and self efficacy of NCAA athletes, and to compare nutrition knowledge and self efficacy of athletes with access to a Sports Nutrition program to these variables in athletes without access. The data for this study was collected using a questionnaire which was developed for the athletes to assess nutrition knowledge and self efficacy. Approval for use of their athletes for the study was granted by both school A and school B on March $15^{\text {th }}$ (see Appendices 2-3). IRB approval was granted on Tuesday, April 12, 2011, after completion of the appropriate application (see Appendix 1).

\section{Subjects}

Male and female student athletes participating in men’s football, men’s wrestling, women’s soccer, and women's swimming and diving at one NCAA Division I University with a Sports Nutrition Program (School B) and one without (School A) were eligible to participate in this study. School A, the University without a Sports Nutrition Department, contracts a Registered Dietitian, who is not full time and is not on campus, to educate the athletes if necessary. School B, the University with a Sports Nutrition Department has two full-time Registered Dietitians on staff, a Training Table and "Landing” (fueling station outside the weight room).

The subjects for this study were select, meaning the specific teams were chosen by the primary investigator in conjunction with the University’s athletic departments. The sports were chosen specifically in order to represent certain types of sports. Also, they were chosen because both Universities had them. Men’s football and women's soccer 
were chosen because they are both stop-and-go sports. Men’s wrestling and women’s swimming and diving were chosen because they are both sports which are more known for having athletes with disordered eating patterns. The athletes were informed by their respective athletic departments of an opportunity to participate in the research. They were informed of a meeting at the end of the spring semester where they would be briefed on the study and asked to participate.

\section{Data Collection Tools}

Nutrition Knowledge and Self Efficacy:

Nutrition knowledge and self-efficacy of each athlete, from all four sports, at each University, were assessed using the survey developed for this study (see Appendix 5). The initial draft of the survey was reviewed by two Registered Dietitians, two Sports Nutritionists, and a Sports Nutrition Graduate Assistant/Intern. The survey was then revised based on recommendations from the reviewers. The survey was then pilot-tested by athletes at a University not a part of the study in order to establish reliability and validity. The athletes who tested the survey were similar to the athletes involved in the study; they were males and females from the same sports being tested. The athletes completed the survey twice, with 2 weeks in-between each test. The correlation between the responses on the initial test and post test of the survey was above $0.908 \%$, establishing that the survey is both reliable and valid.

The survey which was given to each athlete consisted of 33 items to be answered. The first section addressed personal information including e-mail address, height, and weight, demographic information, the sport they participate in, and their college major. 
The e-mail was taken in order to give each athlete their ID number to be used throughout the study. The next section of the survey dealt with nutrition knowledge and addressed macro- and micronutrients, hydration, nutrient timing, supplement use, weight, and calorie intake. The third and final section of the survey addressed self-efficacy of each athlete.

\section{Data Collection Procedure}

Nutrition Knowledge and Self-Efficacy Survey

For this study, the survey portion was conducted in person. Athletes were informed by their respective athletic departments of the meeting for each team which were held at the end of the spring semester at each University. At the meeting, first, a verbal explanation was given of the purpose of the study and each athlete was assured their participation was voluntary and anonymous. After each athlete was given an opportunity to make a decision on participation, informed consents were distributed and they were given time to sign them. The informed consents were then returned to the Primary Investigator. Next, a survey was distributed to each athlete and an explanation was given. After the surveys were completed, they were returned to the primary investigator for further analysis. Lastly, a copy of the informed consent form for their records was also handed out at this time. Athletes were then thanked for their participation and were able to ask any questions they had concerning any portion of the study. 


\section{Data Analysis}

The survey data was entered into an excel spreadsheet. A statistical analysis was performed using JMP-SAS software. The means and standard deviations, and significances (analyzed at $\mathrm{p}=0.05$ ) were found for gender, sport, and each University. The demographic information was analyzed using one-way ANOVA and t-tests, and mean responses differed significantly at $\mathrm{p}<0.05$. The percent responses for sources of nutrition information and counseling and nutrition knowledge between the schools were examined using chi-square analysis, with a significance level set at $\mathrm{p}<0.05$. Mean responses for self-efficacy were examined using one-way ANOVA and t-tests, with a significance level set at $\mathrm{p}<0.05$. Data were compared within each individual University between males and females and between each sport. Data were also compared between each Universitymales and females from School B compared to males and females from School A and each sport at School B to each sport at School A. 


\section{RESULTS}

\section{Description of the Participants}

For this study, 327 NCAA Division I college student athletes were recruited to participate. As shown in Table 1, two Universities were represented in the sample, with approximately $42 \%(n=137)$ of the participants being from School A and 58\% from School B (n=190). Four sports from each University were represented by the sample, with approximately $12 \%(n=39)$ participated in women’s soccer, $10 \%(n=32)$ in women’s swimming and diving, 10\% $(n=34)$ in men's wrestling, and 68\% $(n=222)$ in men’s football. Of the 327 athletes who agreed to participate in the study, approximately 21\% $(n=71)$ were female and $79 \%(n=258)$ were male. There were some athletes who were of mixed race, and because the researcher felt it was inappropriate to use mixed race as an option in the demographic portion of the survey, athletes were able to select more than one race/ethnicity. Because of this the total of the following percentages will be slightly greater than $100 \%$. Of the participants at both Universities, $21 \%(n=70)$ were African American, $2 \%(n=8)$ were Hispanic, $1 \%(n=2)$ were Native American, $0.3 \%(n=1)$ were Asian, 70\% ( $n=227)$ were white, and 7\% $(n=21)$ identified themselves as other. Among all participants at both Universities, 35\% $(n=116)$ were freshman, 24\% $(n=80)$ were sophomores, 25\% (n=83) were juniors, $11 \%(n=36)$ were seniors, and $5 \%(n=12)$ identified themselves as senior+.

A significant amount of athletes from school A were older than those from school B $(\mathrm{p}<0.05)$. However, there was a 16 year old on one of the teams at school B, probably causing this significant difference. The mean age for all athletes from school A was 20.26 
years and the mean age of all athletes from school B was 19.73 years. The mean height of all athletes at school A was 70.92 inches, while the mean height of all athletes at school B was 71.92 inches. The mean weight of all athletes at school A was 202.40 pounds, while the mean weight of all athletes at school B was 209.80 pounds.

Table 1. Demographic information of all college athletes in the study $(n=327)$

\begin{tabular}{|c|c|c|}
\hline & & \\
\hline & School A (n=137) & School B $(n=190)$ \\
\hline \multicolumn{3}{|l|}{ Gender } \\
\hline Male & 102 & 154 \\
\hline Female & 35 & 36 \\
\hline \multicolumn{3}{|l|}{ Sport } \\
\hline Men's Football & 88 & 134 \\
\hline Men's Wrestling & 14 & 20 \\
\hline Women's Soccer & 23 & 16 \\
\hline Women's Swimming/Diving & 12 & 20 \\
\hline \multicolumn{3}{|l|}{ Race/Ethnicity } \\
\hline African American & 26 & 44 \\
\hline Hispanic & 4 & 4 \\
\hline Native American & 2 & 0 \\
\hline Asian & 0 & 1 \\
\hline White & 93 & 134 \\
\hline Other & 12 & 9 \\
\hline \multicolumn{3}{|l|}{ Class Year } \\
\hline Freshman & 39 & 77 \\
\hline Sophomore & 36 & 44 \\
\hline Junior & 38 & 45 \\
\hline Senior & 17 & 19 \\
\hline Senior+ & 7 & $\underline{5}$ \\
\hline
\end{tabular}

Men's Football

Among the football athletes surveyed, those from school A were significantly older than those from school B $(\mathrm{p}<0.05)$. But, as previously stated, there was a football athlete from school B who was 16 years old, most likely contributing to the significance in age. The mean age of football athletes from school A was 20.50 years, while the mean 
age of football athletes from school B was 19.80 years. The football athletes from school B were significantly taller than the football athletes at school A ( $p<0.05)$. The mean height of football athletes from school A was 72.99 inches, while the mean height of football athletes from school B was 73.90 inches. The mean weight of football athletes from school A was 230.73 pounds, while the mean weight of football athletes from school B was 234.77 pounds.

As shown in Table 2, when considering football, $40 \%$ of the participants were from School A ( $\mathrm{n}=88)$ and $60 \%$ from School B $(\mathrm{n}=134)$. Of the football athletes at school A $(n=88), 30 \%(n=26)$ were African American, $0 \%(n=0)$ were Hispanic, $2 \%(n=2)$ were Native American, $0 \%(n=0)$ were Asian, $61 \%(n=54)$ were white, and $7 \%(n=6)$ identified themselves as other. There were some football athletes from school B who were of mixed race, and because the researcher felt it was inappropriate to use mixed race as an option in the demographic portion of the survey, athletes were able to select more than one race/ethnicity. Because of this the total of the following percentages will be slightly greater than $100 \%$. Of the football athletes at school B ( $\mathrm{n}=134), 32 \%(\mathrm{n}=41)$ were African American, $0.1 \%(\mathrm{n}=1)$ were Hispanic, $0 \%(\mathrm{n}=0)$ were Native American, $0.1 \%(n=1)$ were Asian, $64 \%(n=86)$ were white, and $4 \%(n=6)$ identified themselves as other. Among men's football players from school A, 23\% $(n=20)$ were freshman, 21\% $(n=19)$ were sophomores, 31\% $(n=27)$ were juniors, $18 \%(n=16)$ were seniors, and $7 \%$ $(n=6)$ identified themselves as senior+. Among men's football players from school B, $38 \%(n=51)$ were freshman, $21 \%(n=28)$ were sophomores, $25 \%(n=33)$ were juniors, $13 \%(n=18)$ were seniors, and 3\% $(n=4)$ identified themselves as senior+. 
Table 2. Demographic information of men's college football athletes $(n=222)$

\begin{tabular}{lcc}
\hline & School A ( $\mathbf{n = 8 8})$ & School B ( $\mathbf{n = 1 3 4 )}$ \\
$\begin{array}{l}\text { Gender } \\
\text { Male }\end{array}$ & 88 & 134 \\
Race/Ethnicity & & \\
$\quad$ African American & 26 & 41 \\
Hispanic & 0 & 1 \\
Native American & 2 & 0 \\
Asian & 0 & 1 \\
White & 54 & 86 \\
Other & 6 & 6 \\
Class Year & & \\
Freshman & 20 & 51 \\
Sophomore & 19 & 28 \\
Junior & 27 & 33 \\
Senior & 16 & 18 \\
Senior+ & 6 & 4 \\
\hline School A= No FT Sports RD & & \\
School B= FT Sports RD & &
\end{tabular}

Men's Wrestling

The mean age of wrestling athletes from school A was 20.21 years, while the mean age of wrestling athletes from school B was 19.75 years. The mean height of the wrestling athletes from school A was 69.47 inches, while the mean height of wrestling athletes from school B was 68.80 inches. The mean weight of wrestling athletes from school A was 172.00 pounds, while the mean weight of wrestling athletes from school B was 165.80 pounds.

As shown in Table 3, of the wrestling athletes surveyed, 41\% were from School A $(n=14)$ and 59\% from School B $(n=20)$. Of the wrestling athletes at school A $(n=14), 0 \%$ $(n=0)$ were African American, 7\% $(n=1)$ were Hispanic, $0 \%(n=0)$ were Native American, 0\% (n=0) were Asian, 86\% (n=12) were white, and 7\% (n=1) identified 
themselves as other. Of the wrestling athletes at school B $(n=20), 5 \%(n=1)$ were African American, $5 \%(n=1)$ were Hispanic, $0 \%(n=0)$ were Native American, $0 \%(n=0)$ were Asian, 85\% (n=17) were white, and 5\% $(n=1)$ identified themselves as other. Among the wrestling athletes at school A, 43\% (n=6) were freshman, $43 \%(n=6)$ were sophomores, $14 \%(n=2)$ were juniors, $0 \%(n=0)$ were seniors, and $0 \%(n=0)$ identified themselves as senior+. Among the wrestling athletes at school B, 50\% $(n=10)$ were freshman, $25 \%$ $(n=5)$ were sophomores, $25 \%(n=5)$ were juniors, $0 \%(n=0)$ were seniors, and $0 \%(n=0)$ identified themselves as senior+.

Table 3. Demographic information of men's college wrestling athletes $(n=34)$

\begin{tabular}{lcc}
\hline & School A (n=14) & School B (n=20) \\
$\begin{array}{l}\text { Gender } \\
\text { Male }\end{array}$ & 14 & 20 \\
Race/Ethnicity & & \\
African American & 0 & 1 \\
Hispanic & 1 & 1 \\
Native American & 0 & 0 \\
Asian & 0 & 0 \\
White & 12 & 17 \\
Other & 1 & 1 \\
Class Year & & \\
Freshman & 6 & 10 \\
Sophomore & 6 & 5 \\
Junior & 2 & 5 \\
Senior & 0 & 0 \\
Senior+ & 0 & 0 \\
\hline Schol A No & & \\
\hline
\end{tabular}

School A= No FT Sports RD

School B= FT Sports RD

Women's Soccer

The mean age of the women’s soccer athletes from school A was 19.70 years, while the mean age of women's soccer athletes from school B was 19.56 years. The mean 
height of the soccer athletes from school A was 65.63 inches, while the mean height of soccer athletes from school B was 65.63 inches. The mean weight of soccer athletes from school A was 141.91 pounds, while the mean weight of the soccer athletes from school B was 136.25 pounds.

As shown in Table 4, of the women's soccer athletes surveyed, 59\% were from School A (n=23) and 41\% from School B $(n=16)$. Of the soccer athletes from school A $(n=23), 0 \%(n=0)$ were African American, $13 \%(n=3)$ were Hispanic, $0 \%(n=0)$ were Native American, $0 \%(n=0)$ were Asian, $74 \%(n=17)$ were white, and $13 \%(n=3)$ identified themselves as other. Of the soccer athletes at school $B(n=16), 6 \%(n=1)$ were African American, 6\% $(n=1)$ were Hispanic, $0 \%(n=0)$ were Native American, $0 \%(n=0)$ were Asian, $88 \%(n=14)$ were white, and $0 \%(n=0)$ identified themselves as other. Among the soccer athletes at school A, 40\% $(n=9)$ were freshman, 30\% $(n=7)$ were sophomores, $30 \%(n=7)$ were juniors, $0 \%(n=0)$ were seniors, and $0 \%(n=0)$ identified themselves as senior+. Among the soccer athletes at school B, 56\% (n=9) were freshman, $19 \%(n=3)$ were sophomores, $13 \%(n=2)$ were juniors, $6 \%(n=1)$ were seniors, and $6 \%$ $(n=1)$ identified themselves as senior+. 
Table 4. Demographic information of women's college soccer athletes $(n=39)$

\begin{tabular}{|c|c|c|}
\hline & \multicolumn{2}{|c|}{$\%$} \\
\hline & School A $(n=23)$ & School B $(n=16)$ \\
\hline \multicolumn{3}{|l|}{ Gender } \\
\hline Female & 23 & 16 \\
\hline \multicolumn{3}{|l|}{ Race/Ethnicity } \\
\hline African American & 0 & 1 \\
\hline Hispanic & 3 & 1 \\
\hline Native American & 0 & 0 \\
\hline Asian & 0 & 0 \\
\hline White & 17 & 14 \\
\hline Other & 3 & 0 \\
\hline \multicolumn{3}{|l|}{ Class Year } \\
\hline Freshman & 9 & 9 \\
\hline Sophomore & 7 & 3 \\
\hline Junior & 7 & 2 \\
\hline Senior & 0 & 1 \\
\hline Senior + & 0 & 1 \\
\hline
\end{tabular}

School A= No FT Sports RD

School B= FT Sports RD

Women's Swimming/Diving

The mean age of the women's swimming/diving athletes from school A was 19.58 years, while the mean age of women's swimming/diving athletes from school B was 19.40 years. The mean height of the swimming/diving athletes from school A was 67.58 inches, while the mean height of swimming/diving athletes from school B was 66.83 inches. The mean weight of swimming/diving athletes from school A was 146.04 pounds, while the mean weight of the swimming/diving athletes from school B was 148.25 pounds.

As shown in Table 5, of the women's swimming/diving athletes surveyed, 38\% were from School A $(n=12)$ and 62\% from School B $(n=20)$. Of the swimming/diving athletes from school A ( $n=12), 0 \%(n=0)$ were African American, $0 \%(n=0)$ were Hispanic, $0 \%(n=0)$ were Native American, $0 \%(n=0)$ were Asian, $83 \%(n=10)$ were 
white, and $17 \%(n=2)$ identified themselves as other. Of the swimming/diving athletes at school B (n=20), 5\% (n=1) were African American, 5\% (n=1) were Hispanic, 0\% (n=0) were Native American, $0 \%(n=0)$ were Asian, $85 \%(n=17)$ were white, and $5 \%(n=1)$ identified themselves as other. Among the swimming/diving athletes at school A, 33\% $(n=4)$ were freshman, $33 \%(n=4)$ were sophomores, $18 \%(n=2)$ were juniors, $8 \%(n=1)$ were seniors, and $8 \%(n=1)$ identified themselves as senior+. Among the swimming/diving athletes from school B, 35\% $(n=7)$ were freshman, $40 \%(n=8)$ were sophomores, $25 \%(n=5)$ were juniors, $0 \%(n=0)$ were seniors, and $0 \%(n=0)$ identified themselves as senior+.

Table 5. Demographic information of women's college swimming/diving athletes $(n=32)$

\begin{tabular}{|c|c|c|}
\hline & \multicolumn{2}{|c|}{$\%$} \\
\hline & School A (n=12) & School B $(n=20)$ \\
\hline \multicolumn{3}{|l|}{ Gender } \\
\hline Female & 12 & 20 \\
\hline \multicolumn{3}{|l|}{ Race/Ethnicity } \\
\hline African American & 0 & 1 \\
\hline Hispanic & 0 & 1 \\
\hline Native American & 0 & 0 \\
\hline Asian & 0 & 0 \\
\hline White & 10 & 17 \\
\hline Other & 2 & 1 \\
\hline \multicolumn{3}{|l|}{ Class Year } \\
\hline Freshman & 4 & 7 \\
\hline Sophomore & 4 & 8 \\
\hline Junior & 2 & 5 \\
\hline Senior & 1 & 0 \\
\hline Senior+ & 1 & 0 \\
\hline
\end{tabular}

School A= No FT Sports RD

School B= FT Sports RD

\section{Sources of Nutrition Counseling and Information}

As shown in Table 6, a significant amount more student athletes from school B (University with sports nutrition department) reported having access to nutrition 
counseling compared to athletes from school A (University without sports nutrition department) ( $\mathrm{p}<0.05)$. Approximately 99\% of student athletes from school B reported having access to nutrition counseling, while $83 \%$ from school A reported having access to nutrition counseling. When asked whether they actively seek out or read nutrition information, a significantly larger amount of student athletes from school B stated they actively seek out or read nutrition information $(\mathrm{p}<0.05)$. Of all of the athletes surveyed, $66 \%$ from school B stated they do seek out nutrition information, while $40 \%$ from school A stated they do. The most frequent responses for where athletes from school A seek out nutrition information were family, strength and conditioning coach, and the internet. The most frequent responses for where athletes from school B seek out nutrition information included teammates, family, strength and conditioning coach, athletic trainer, registered dietitian, and the internet. A significantly higher number of athletes from school B sought nutrition information from teammates, strength and conditioning coach, and registered dietitian $(\mathrm{p}<0.05)$. Of the $33 \%$ of athletes from school B who stated they do not actively seek out or read nutrition information, most felt it was because it is not a major concern. However, a significantly larger amount of the $58 \%$ of athletes from school A who stated they do not seek out nutrition information, said they didn't because it is not a major concern $(\mathrm{p}<0.05)$. When the athletes were asked if they read the nutrition facts label when selecting a food to eat, a significantly higher number of them from school B reported doing so $(\mathrm{p}<0.05)$. Among all of the athletes from school A, 58\% reported they do, while $78 \%$ from school B reported they do. The athletes who selected that they do read the nutrition facts label were then asked what they look for. The most common responses from the athletes at school A were calories, fat grams, protein, and 
carbohydrates. The most common responses from the athletes at school B were calories, fat grams, saturated fat, protein, and carbohydrates. A significant more number of athletes from school B stated they look at the nutrition facts label for fat grams, saturated fat, and protein $(\mathrm{p}<0.05)$. Of the $42 \%$ of athletes from school A who do not read the nutrition facts label most stated it was because it is not important. Of the $22 \%$ of athletes from school B who do not read the nutrition facts label most stated it was because it is not important or they do not know what to look for. A significantly larger amount of athletes from school A stated they do not look at the nutrition facts label because it is not important and for other reasons ( $\mathrm{p}<0.05)$. 
Table 6. Comparing Sources of Nutrition Counseling and Information for all athletes at both School A and School B $(n=327)$

\begin{tabular}{|c|c|c|c|c|}
\hline & \multicolumn{2}{|c|}{$\%$} & \multirow[b]{2}{*}{$\mathrm{X}^{2}$} & \multirow[b]{2}{*}{$\underset{\text { value }}{\mathbf{p}<}$} \\
\hline & $\begin{array}{r}\text { School A } \\
(\mathbf{n}=137)\end{array}$ & $\begin{array}{c}\text { School B } \\
(n=190)\end{array}$ & & \\
\hline \multicolumn{5}{|l|}{ Do you have access to nutrition counseling? } \\
\hline Yes & 83 & 99 & & \\
\hline No & 10 & 0.5 & 30.58 & $<0.0001^{*}$ \\
\hline Don't Know & 7 & 0.5 & & \\
\hline \multicolumn{5}{|l|}{ Do you actively seek out or read nutrition information? } \\
\hline Yes & 40 & 66 & & \\
\hline No & 58 & 33 & 21.69 & $<0.0001^{*}$ \\
\hline Don't Know & 2 & 1 & & \\
\hline \multicolumn{5}{|l|}{ If you do, from where?** } \\
\hline Teammates & 12 & 26 & 9.75 & $0.0018^{*}$ \\
\hline Magazines & 15 & 14 & 0.19 & 0.6626 \\
\hline Family & 23 & 21 & 0.13 & 0.7151 \\
\hline Doctor & 7 & 7 & 0.01 & 0.9325 \\
\hline Strength and Conditioning Coach & 28 & 43 & 7.79 & $0.0053 *$ \\
\hline Supplement Store & 10 & 8 & 0.55 & 0.4591 \\
\hline Athletic Trainer & 18 & 20 & 0.24 & 0.6238 \\
\hline Registered Dietitian & 15 & 24 & 4.14 & $0.0419 *$ \\
\hline Internet & 26 & 28 & 0.30 & 0.5834 \\
\hline Other & 4 & 6 & 0.31 & 0.5751 \\
\hline \multicolumn{5}{|l|}{ If you don't, why not?** } \\
\hline No time & 9 & 11 & 0.45 & 0.5041 \\
\hline It is not a major concern & 36 & 15 & 19.63 & $<0.0001^{*}$ \\
\hline You already have enough nutrition knowledge & 9 & 5 & 1.56 & 0.2120 \\
\hline Other & 8 & 1 & 10.61 & $0.0011^{*}$ \\
\hline \multicolumn{5}{|c|}{ Do you read the nutrition facts label when selecting a food to eat? } \\
\hline Yes & 58 & 78 & & \\
\hline No & 42 & 22 & 14.25 & $0.0002 *$ \\
\hline Don't Know & 0 & 0 & & \\
\hline \multicolumn{5}{|l|}{ If so, what do you look for?** } \\
\hline Calories & 55 & 64 & 2.24 & 0.1349 \\
\hline Sodium & 18 & 22 & 0.55 & 0.4573 \\
\hline Fat grams & 28 & 55 & 23.71 & $<0.0001^{*}$ \\
\hline Fiber & 10 & 17 & 2.98 & 0.0844 \\
\hline Saturated Fat & 15 & 31 & 11.08 & $0.0009 *$ \\
\hline Protein & 42 & 59 & 10.23 & $0.0014 *$ \\
\hline Monounsaturated Fat & 6 & 9 & 1.12 & 0.2901 \\
\hline Carbohydrates & 31 & 41 & 3.38 & 0.0660 \\
\hline Polyunsaturated Fat & 7 & 8 & 0.39 & 0.5311 \\
\hline Calcium, iron, vitamins & 11 & 17 & 2.30 & 0.1291 \\
\hline Other & 4 & 2 & 1.37 & 0.2426 \\
\hline \multicolumn{5}{|l|}{ If not, what are the reasons?** } \\
\hline It is too time consuming & 9 & 5 & 2.14 & 0.1436 \\
\hline I don't know what to look for & 10 & 7 & 1.18 & 0.2769 \\
\hline It is not important & 20 & 8 & 9.75 & $0.0018^{*}$ \\
\hline Other & 8 & 2 & 8.20 & $0.0042^{*}$ \\
\hline
\end{tabular}

*Based on chi-square analysis, percent response differed significantly at $\mathrm{p}<0.05$ **Could check none or all that apply

School A= No FT Sports RD

School B= FT Sports RD 


\section{Men's Football}

As shown in Table 7, a significant amount more of men's football athletes at School B (University with sports nutrition department) reported having access to nutrition counseling than men's football athletes at school A (University without sports nutrition department) ( $<$ 0.05). Approximately 87\% of football players from school A reported having access to nutrition counseling, while $100 \%$ of football athletes from school B reported having access to nutrition counseling. When asked whether they actively seek out or read nutrition information, a significantly larger amount of football athletes from school B stated they actively seek out or read nutrition information ( $\mathrm{p}<$ 0.05). Of the football athletes surveyed, $70 \%$ from school B stated they do seek out nutrition information, while 34\% from school A stated they do. The most frequent responses for where football athletes from school A seek out nutrition information were family, strength and conditioning coach, and the internet. The most frequent responses for where football athletes from school B seek out nutrition information included teammates, family, strength and conditioning coach, athletic trainer, registered dietitian, and the internet. A significantly higher number of football athletes from school B sought nutrition information from teammates, strength and conditioning coaches, athletic trainers, and registered dietitians $(\mathrm{p}<0.05)$. Of the $29 \%$ of football athletes from school B who stated they do not actively seek out or read nutrition information, most felt it was because it is not a major concern or because they didn't have enough time. However, a significantly larger amount of the $63 \%$ of football athletes from school A who stated they do not seek out nutrition information, said they didn't because it is not a major concern ( $\mathrm{p}$ $<0.05)$. When the football athletes were asked if they read the nutrition facts label when 
selecting a food to eat, a significantly higher number of them from school B reported doing so ( $\mathrm{p}<0.05)$. Among the football athletes from school A, 57\% reported they do, while $76 \%$ from school B reported they do. The football athletes who selected that they do read the nutrition facts label were then asked what they look for. The most common responses from the football athletes at school A were calories, fat grams, protein, and carbohydrates. The most common responses from the football athletes at school B were calories, fat grams, saturated fat, protein, and carbohydrates. A significantly higher number of football athletes from school B stated they look at the nutrition facts label for fat grams, saturated fat, and protein ( $p<0.05$ ). Of the $43 \%$ of football athletes from school A who do not read the nutrition facts label most stated it was because it is not important. Of the $24 \%$ of football athletes from school B who do not read the nutrition facts label most stated it was because it is not important, they do not know what to look for, or it's too time consuming. A significantly larger amount of football athletes from school A stated they do not look at the nutrition facts label because it is not important and for other reasons $(\mathrm{p}<0.05)$. 
Table 7. Comparing Sources of Nutrition Counseling and Information of football athletes at both School A and School B (n=222)

$\begin{array}{cccc}\text { School A } \\ (\mathbf{n = 8 8})\end{array} \quad \begin{gathered}\text { School B } \\ (\mathbf{n = 1 3 4 )}\end{gathered} \quad X^{2} \quad \mathbf{p}<$ value

Do you have access to nutrition counseling?

Yes

No

Don't Know

Do you actively seek out or read nutrition information?

Yes

No

Don't Know

If you do, from where?**

Teammates

Magazines

Family

Doctor

Strength and Conditioning Coach

Supplement Store

Athletic Trainer

Registered Dietitian

Internet

Other

87

7

6

34

63

3

7

14

18

3

25

10

14

11

20

3

If you don't, why not?**

No time

It is not a major concern

You already have enough nutrition knowledge

Other

Do you read the nutrition facts label when selecting a

food to eat?

Yes

No

Don't Know

If so, what do you look for?**

Calories

Sodium

Fat grams

Fiber

Saturated Fat

Protein

Monounsaturated Fat

Carbohydrates

Polyunsaturated Fat

Calcium, iron, vitamins

Other

If not, what are the reasons?**

It is too time consuming

I don't know what to look for

It is not important

Other

0

$87 \quad 100$

0

0

70

29

1

26

26
11

11

18

8
50

9

24

23

27

6

$21.34<0.0001^{*}$

0

(1)

$28.13<0.0001 *$

1

$14.50<0.0001^{*}$

$0.32 \quad 0.5742$

$0.01 \quad 0.9388$

$2.20 \quad 0.1380$

$14.69 \quad 0.0001 *$

$0.11 \quad 0.7391$

$4.02 \quad 0.0449 *$

$5.03 \quad 0.0249 *$

$\begin{array}{ll}5.14 & 0.2863\end{array}$

$0.75 \quad 0.3853$

$\begin{array}{cccc}9 & 10 & 0.10 & 0.7531 \\ 40 & 13 & 21.72 & <0.0001^{*} \\ 8 & 6 & 0.34 & 0.5576 \\ 9 & 0 & 15.34 & <0.0001^{*}\end{array}$

$57 \quad 76$

$43 \quad 24$

$9.07 \quad 0.0026^{*}$

0

$\begin{array}{llll}55 & 60 & 0.58 & 0.4473\end{array}$

$\begin{array}{llll}13 & 16 & 0.66 & 0.4180\end{array}$

$24 \quad 54$

$8 \quad 14$

$10 \quad 30$

$20.17<0.0001^{*}$

$2.08 \quad 0.1491$

$12.89 \quad 0.0003^{*}$

$\begin{array}{llll}50 & 63 & 3.93 & 0.0475 *\end{array}$

$\begin{array}{llll}3 & 8 & 2.24 & 0.1344\end{array}$

$\begin{array}{llll}30 & 36 & 0.95 & 0.3301\end{array}$

$\begin{array}{lccc}6 & 7 & 0.27 & 0.6015\end{array}$

$\begin{array}{llll}10 & 14 & 0.77 & 0.3803\end{array}$

$\begin{array}{llll}5 & 2 & 0.90 & 0.3427\end{array}$

*Based on chi-square analysis, percent response differed significantly at $\mathrm{p}<0.05$

**Could check none or all that apply

School A= No FT Sports RD

School B= FT Sports RD 
Men's Wrestling

As shown in Table 8, a significant amount more of men's wrestling athletes at School B (University with sports nutrition department) reported having access to nutrition counseling than men's wrestling athletes at school A (University without sports nutrition department) $(\mathrm{p}<0.05)$. Approximately 36\% of wrestlers from school A reported having access to nutrition counseling, while 95\% of wrestlers from school B reported having access to nutrition counseling. Of the men's wrestling athletes surveyed, 70\% from school B stated they do seek out nutrition information, while 64\% from school A stated they do. The most frequent responses for where wrestlers from school A seek out nutrition information were teammates, family, strength and conditioning coach, athletic trainer, and the internet. The most frequent responses for where wrestlers from school B seek out nutrition information included teammates, strength and conditioning coach, registered dietitian, and the internet. A significantly higher number of wrestling athletes from school A sought nutrition information from a doctor $(p<0.05)$. Of the $25 \%$ of wrestling athletes from school B who stated they do not actively seek out or read nutrition information, most felt it was because they didn't have enough time. Of the 36\% of wrestling athletes from school A who stated they do not seek out nutrition information, said they didn't because it is not a major concern. When the wrestling athletes were asked if they read the nutrition facts label when selecting a food to eat $64 \%$ of wrestlers from school A reported they do, while 90\% from school B reported they do. The wrestling athletes who selected that they do read the nutrition facts label were then asked what they look for. The most common responses from the wrestlers at school A were calories, sodium, fat grams, protein, and carbohydrates. The most common responses from the 
wrestlers at school B were calories, fat grams, saturated fat, protein, and carbohydrates, and calcium, iron, and vitamins. Of the $36 \%$ of wrestling athletes from school A who do not read the nutrition facts label most stated it was because it is not important. Of the $10 \%$ of wrestling athletes from school B who do not read the nutrition facts label most stated it was because it is not important or they do not know what to look for. 
Table 8. Comparing Sources of Nutrition Counseling and Information of wrestling athletes at both

School A and School B (n=34)

$\%$

$\begin{array}{cc}\text { School A } \\ (n=14)\end{array} \quad \begin{gathered}\text { School B } \\ (n=20)\end{gathered} \quad X^{2} \quad p<$ value

Do you have access to nutrition counseling?

Yes
No
Don't Know

Do you actively seek out or read nutrition information?

Yes

No

Don't Know

If you do, from where?**

Teammates

Magazines

Family

Doctor

Strength and Conditioning Coach

Supplement Store

Athletic Trainer

Registered Dietitian

Internet

Other

If you don't, why not?**

No time

It is not a major concern

You already have enough nutrition knowledge

Other

Do you read the nutrition facts label when selecting a food to eat?

Yes

No

Don't Know

If so, what do you look for?**

Calories

Sodium

Fat grams

Fiber

Saturated Fat

Protein

Monounsaturated Fat

Carbohydrates

Polyunsaturated Fat

Calcium, iron, vitamins

Other

If not, what are the reasons?**

It is too time consuming

I don't know what to look for

It is not important

Other
36

36

28

64

36

0

$\begin{array}{llll}43 & 45 & 0.02 & 0.9014\end{array}$

$\begin{array}{llll}29 & 10 & 1.93 & 0.1644\end{array}$

43

21

57

21

36

14

57

7

0

21

7

0

$\begin{array}{ccc}95 & & \\ 0 & 16.5 & 0.0003^{*} \\ 5 & & \\ & & \\ 70 & & \\ 25 & 1.42 & 0.4922 \\ 5 & & \\ & & \\ 45 & 0.02 & 0.9014 \\ 10 & 1.93 & 0.1644 \\ 25 & 1.19 & 0.2751 \\ 0 & 5.75 & 0.0165^{*} \\ 40 & 0.97 & 0.3236 \\ 10 & 0.84 & 0.3584 \\ 10 & 3.32 & 0.0684 \\ 30 & 1.18 & 0.2768 \\ 40 & 0.97 & 0.3236 \\ 10 & 0.09 & 0.7701 \\ & & \\ 15 & 3.39 & 0.0658 \\ 10 & 0.84 & 0.3584 \\ 0 & 1.82 & 0.1775 \\ 0 & 0.00 & \\ & & \end{array}$

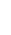

*Based on chi-square analysis, percent response differed significantly at $\mathrm{p}<0.05$

**Could check none or all that apply

School A= No FT Sports RD

School B= FT Sports RD 


\section{Women's Soccer}

As shown in Table 9, approximately 87\% of women's soccer athletes from school A reported having access to nutrition counseling, while $100 \%$ of women's soccer athletes from school B reported having access to nutrition counseling. When asked whether they actively seek out or read nutrition information, of the women's soccer athletes surveyed, 31\% from school B stated they do seek out nutrition information, while 39\% from school A stated they do. The most frequent responses for where women's soccer athletes from school A seek out nutrition information were strength and conditioning coaches and the internet. The most frequent responses for where women's soccer athletes from school B seek out nutrition information included strength and conditioning coaches, family, and teammates. Of the $69 \%$ of women's soccer athletes from school B who stated they do not actively seek out or read nutrition information, most felt it was because it is not a major concern. Of the $61 \%$ of women's soccer athletes from school A, who stated they do not seek out nutrition information, most felt it was because it is not a major concern. When the women's soccer athletes were asked if they read the nutrition facts label when selecting a food to eat, $61 \%$ from school A reported they do, while $56 \%$ from school B reported they do. The soccer athletes who selected that they do read the nutrition facts label were then asked what they look for. The most common responses from the women's soccer athletes at school A were calories, sodium, fat grams, saturated fat, and carbohydrates. The most common responses from the women's soccer athletes at school B were calories, sodium, fat grams, protein, and carbohydrates. Of the $39 \%$ of women's soccer athletes from school A who do not read the nutrition facts label most stated it was because it is not important or they don't know what to look for. Of the $24 \%$ of women's 
soccer athletes from school B who do not read the nutrition facts label most stated it was because it is not important. 
Table 9. Comparing Sources of Nutrition Counseling and Information of women's soccer athletes at both School A and School B (n=39)

Do you have access to nutrition counseling?

Yes

No

Don't Know

Do you actively seek out or read nutrition information?

Yes

No

Don't Know

If you do, from where?**

Teammates

Magazines

Family

Doctor

Strength and Conditioning Coach

Supplement Store

Athletic Trainer

Registered Dietitian

Internet

Other

If you don't, why not?**

No time

It is not a major concern

You already have enough nutrition knowledge

Other

$\begin{array}{lccc}\operatorname{Sch}_{(\mathbf{n}=23)} \% & \begin{array}{c}\text { School B } \\ (\mathbf{n}=16)\end{array} & \mathbf{X}^{2} & \begin{array}{c}\mathbf{p}< \\ \text { value }\end{array}\end{array}$

you read the nutrition facts label when selecting a food to eat?

Yes

No

Don't Know

If so, what do you look for?**

Calories

Sodium

Fat grams

Fiber

Saturated Fat

Protein

Monounsaturated Fat

Carbohydrates

Polyunsaturated Fat

Calcium, iron, vitamins

Other

$\begin{array}{cccc}87 & 100 & & \\ 9 & 0 & 3.34 & 0.1882 \\ 4 & 0 & & \\ 39 & 31 & & \\ 61 & 69 & 0.26 & 0.6125 \\ 0 & 0 & & \end{array}$

$\begin{array}{llll}4 & 19 & 2.12 & 0.1450\end{array}$

$\begin{array}{llll}9 & 6 & 0.08 & 0.7756\end{array}$

$\begin{array}{llll}22 & 19 & 0.05 & 0.8195\end{array}$

$\begin{array}{llll}4 & 0 & 1.07 & 0.3000\end{array}$

$\begin{array}{llll}26 & 25 & 0.01 & 0.9390\end{array}$

$\begin{array}{cccc}0 & 0 & 0.00 & \\ 22 & 6 & 1.92 & 0.1658\end{array}$

$\begin{array}{llll}22 & 13 & 0.57 & 0.4517\end{array}$

$\begin{array}{llll}26 & 6 & 2.82 & 0.0928\end{array}$

$\begin{array}{llll}4 & 0 & 1.07 & 0.3000\end{array}$

$\begin{array}{llll}13 & 19 & 0.23 & 0.6293\end{array}$

$\begin{array}{llll}35 & 31 & 0.05 & 0.8176\end{array}$

$\begin{array}{llll}13 & 0 & 3.34 & 0.0676\end{array}$

$\begin{array}{llll}9 & 6 & 0.08 & 0.7756\end{array}$

not, what are the reasons?**

It is too time consuming

$\begin{array}{llllll}\text { I don't know what to look for } & 17 & 6 & 1.14 & 0.2865\end{array}$

$\begin{array}{llllll}22 & 25 & 0.06 & 0.8126\end{array}$

$\begin{array}{lrrrr}\text { Other } & 4 & 0 & 1.07 & 0.3000\end{array}$

*Based on chi-square analysis, percent response differed significantly at $\mathrm{p}<0.05$

**Could check none or all that apply

School A= No FT Sports RD

School B= FT Sports RD 
Women's Swimming/Diving

As shown in Table 10, approximately 100\% of women’s swimming and diving athletes from school A reported having access to nutrition counseling, while 95\% of swimming and diving athletes from school B reported having access to nutrition counseling. When asked whether they actively seek out or read nutrition information, $58 \%$ of women's swimming and diving athletes from school A stated they do seek out nutrition information, while $65 \%$ from school B stated they do. The most frequent responses for where women's swimming and diving athletes from school A seek out nutrition information were teammates and family. The most frequent responses for where women’s swimming and diving athletes from school B seek out nutrition information included magazines, family, registered dietitians, and the internet. Of the $42 \%$ of women's swimming and diving athletes from school A, who stated they do not actively seek out or read nutrition information, most felt it was because it is not a major concern. Of the $35 \%$ of women's swimming and diving athletes from school B who stated they do not seek out nutrition information, most felt it was because it is not a major concern. When the women's swimming and diving athletes were asked if they read the nutrition facts label when selecting a food to eat, a significantly higher number of them from school B reported doing so $(\mathrm{p}<0.05)$. Among the women’s swimming and diving athletes from school A, 58\% reported they do, while 95\% from school B reported they do. The swimming and diving athletes who selected that they do read the nutrition facts label were then asked what they look for. The most common responses from the swimming and diving athletes at school A were calories, sodium, fat grams, protein, and carbohydrates. The most common responses from the swimming and diving athletes at 
school B were calories, sodium, fat grams, fiber, saturated fat, protein, carbohydrates, and calcium, iron, and vitamins. A significantly higher number of women's swimming and diving athletes from school B stated they look at the nutrition facts label for calories and fat grams ( $\mathrm{p}<0.05)$. Of the $42 \%$ of women's swimming and diving athletes from school A who do not read the nutrition facts label most stated it was because it is too time consuming or they don't know what to look for. Of the 5\% of women's swimming and diving athletes from school B who do not read the nutrition facts label all stated it was because it is not important. A significantly larger amount of women's swimming and diving athletes from school A stated they do not look at the nutrition facts label because it is too time consuming $(\mathrm{p}<0.05)$. 
Table 10. Comparing Sources of Nutrition Counseling and Information of women's swimming/diving athletes at both School A and School B (n=32)

Do you have access to nutrition counseling?

Yes

No

Don't Know

Do you actively seek out or read nutrition information?

Yes

No

Don't Know

If you do, from where?**

eammates

Magazines

Family

Doctor

Strength and Conditioning Coach

Supplement Store

Athletic Trainer

Registered Dietitian

Internet

Other

If you don't, why not?**

No time

It is not a major concern

You already have enough nutrition knowledge

Other

Do you read the nutrition facts label when selecting a

food to eat?

Yes

No

Don't Know

If so, what do you look for?**

Calories

Sodium

Fat grams

Fiber

Saturated Fat

Protein

Monounsaturated Fat

Carbohydrates

Polyunsaturated Fat

Calcium, iron, vitamins

Other

$\begin{array}{lccc}\operatorname{School}_{(\mathbf{n}=12)} \% & \begin{array}{c}\text { School B } \\ (\mathbf{n}=20)\end{array} & X^{2} \quad \mathbf{p}<\text { value }\end{array}$

$100 \quad 95$

$0 \quad 0$

$0.96 \quad 0.3274$

$58 \quad 65$

$42 \quad 35$

$0 \quad 0$

$0.14 \quad 0.7068$

$\begin{array}{llll}33 & 15 & 1.44 & 0.2308\end{array}$

$\begin{array}{llll}25 & 40 & 0.77 & 0.3812\end{array}$

$\begin{array}{llll}33 & 40 & 0.14 & 0.7051\end{array}$

$\begin{array}{llll}17 & 10 & 0.30 & 0.5861\end{array}$

$\begin{array}{llll}25 & 15 & 0.48 & 0.4882\end{array}$

$\begin{array}{llll}17 & 5 & 1.16 & 0.2818\end{array}$

$\begin{array}{llll}25 & 15 & 0.48 & 0.4882\end{array}$

$\begin{array}{llll}25 & 30 & 0.09 & 0.7595\end{array}$

$\begin{array}{llll}25 & 45 & 1.32 & 0.2509\end{array}$

$\begin{array}{llll}8 & 5 & 0.14 & 0.7103\end{array}$

$\begin{array}{llll}8 & 5 & 0.14 & 0.7103\end{array}$

$\begin{array}{llll}25 & 20 & 0.11 & 0.7419\end{array}$

$\begin{array}{llll}8 & 10 & 0.03 & 0.8747\end{array}$

$\begin{array}{llll}8 & 5 & 0.14 & 0.7103\end{array}$

not, what are the reasons?**

It is too time consuming

I don't know what to look for

42

6.64

$0.0100 *$

It is not important

Other

*Based on chi-square analysis, percent response differed significantly at $\mathrm{p}<0.05$ **Could check none or all that apply

School A= No FT Sports RD

School B= FT Sports RD 


\section{Nutrition Knowledge of the Athletes}

As shown in Table 11, 100\% of all athletes surveyed from school A, and 98\% of all athletes surveyed from school B responded that they believe having a nutritious diet would improve their athletic performance. A significantly higher number of all athletes at school B responded that they are aware of how many calories they need to consume every day to promote their best athletic performance $(\mathrm{p}<0.05)$. Of all athletes surveyed from school A, 35\% responded that they were aware of their calorie needs, and of all athletes surveyed from school B, 68\% responded that were aware of their calorie needs. A significantly higher number of all athletes surveyed at school B responded that they believe having a sports nutritionist at their University is or would be helpful to them as an athlete $(\mathrm{p}<0.05)$. Of all athletes surveyed at school A, 93\% responded that they believe having a sports nutritionist would be beneficial to them, while $99 \%$ of all athletes surveyed at school B responded that they believe having a sports nutritionist available to them is beneficial. Of all athletes surveyed at school A, 61\% responded correctly, that carbohydrates and fats are the main sources of energy for the muscles and $62 \%$ of all athletes surveyed at school B answered correctly. Of all athletes surveyed, 29\% from both school A and school B answered correctly, that protein is not the primary source of energy for muscles. Of all athletes surveyed at school A, 37\% answered correctly, and of all athletes from school B, 32\% answered correctly that protein supplements are not needed in addition to food for muscle growth and development. Of all athletes surveyed at school A, 52\% answered correctly, and of all athletes at school B, 55\% answered correctly that the vast majority of supplements sold have not been tested for effectiveness or safety. Of all athletes surveyed at both school A and school B, 99\% answered correctly 
that consuming fruits and vegetables every day is important in order to get necessary vitamins and minerals. Of all athletes surveyed at school A, 75\% answered correctly, and of all athletes from school B, 79\% answered correctly that high fat foods should be reduced in the diet. Of all athletes surveyed from school A, 9\% answered correctly, and of all athletes surveyed from school B, 16\% answered correctly that vitamin and mineral supplements do not provide energy to the body. Of all athletes surveyed at school A, 69\% responded that their coaches have encouraged them to either gain or lose weight. Of all athletes surveyed at school B, 67\% responded that their coaches have encouraged them to either gain or lose weight. A significantly higher number of all athletes surveyed at school B responded correctly that it is recommended to consume sports drinks during practices lasting longer than 1 hour $(\mathrm{p}<0.05)$. Of all athletes surveyed at school A, 66\% responded correctly, and of all athletes surveyed at school B, 90\% responded correctly that it is recommended to consume sports drinks during practices lasting longer than 1 hour. Of all athletes surveyed at school A, 74\% responded correctly, and of all athletes surveyed at school B, 70\% responded correctly that sports drinks like Gatorade and Powerade should not be consumed all throughout the day. A significantly higher number of all athletes surveyed at school A responded correctly that during 2-a-days or heavy practice days they should eat more calories $(\mathrm{p}<0.05)$. Of all athletes surveyed at school A, 99\% responded correctly, and of all athletes surveyed at school B, 92\% responded correctly that during 2-a-days or heavy practice days they should eat more calories. Of all athletes surveyed at school A, 69\% responded correctly, and of all athletes surveyed at school B, 72\% responded correctly that their calorie needs do change when they are inactive. Of all athletes surveyed from school A and from school B, 87\% responded 
correctly that eating within 45 minutes of a workout is important. Of all athletes surveyed from school A and from school B, 99\% responded correctly that milk is a good source of calcium and vitamin D. Of all athletes surveyed at school A and from school B, 94\% responded correctly that whole grain breads are a good source of fiber. Of all athletes surveyed from school A, 91\% responded correctly, and from school B, 94\% responded correctly that a turkey breast is a good source of lean protein. 
Table 11. Comparing Nutrition Knowledge all athletes at both School A and School B ( $n=327)$

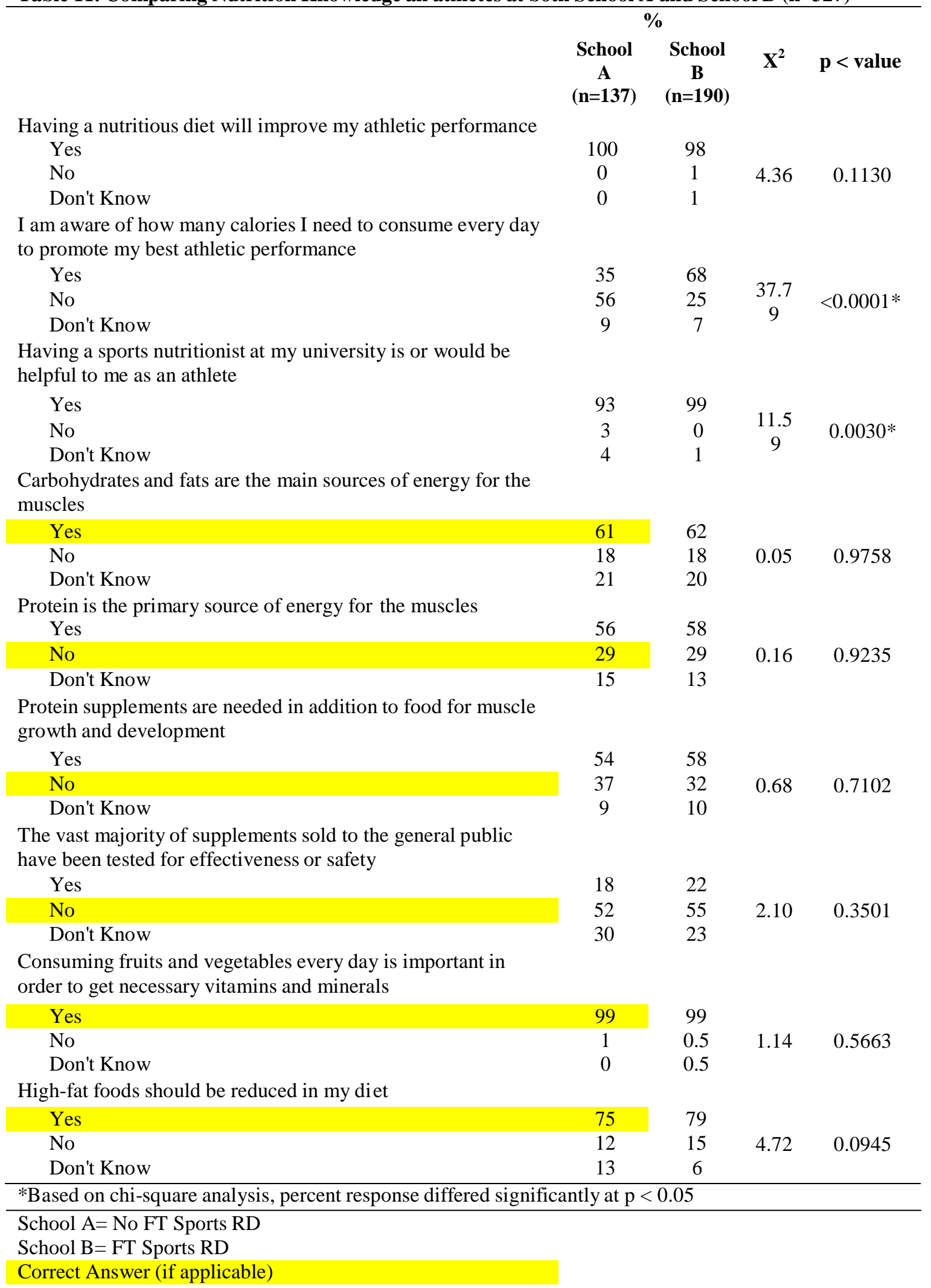


Vitamin and mineral supplements provide energy to my body

Yes

\begin{tabular}{|c|c|}
\hline $\begin{array}{c}\text { School } \\
\text { A } \\
(n=137)\end{array}$ & $\begin{array}{c}\text { School } \\
\text { B } \\
(n=190)\end{array}$ \\
\hline
\end{tabular}

No

$\begin{array}{cc}79 & 72 \\ 9 & 16 \\ 12 & 12\end{array}$

$4.28 \quad 0.1177$

Don't Know

16

My coaches have encouraged me to either gain or lose weight

Yes

$69 \quad 67$

No

Don't Know

$30 \quad 28$

3.62

0.1635

It is recommended to consume sports drinks during practices lasting longer than 1 hour

Yes

No

Don't Know

22

$30.88<0.0001^{*}$

Sports drinks like Gatorade and Powerade are better than drinking water and should be consumed all throughout the day

Yes

$14-22$

No

Don't Know

During 2-a-days or heavy practice days I should eat more calories

$\begin{array}{lll}\text { Yes } & 99 & 92\end{array}$

No

Don't Know

4

$12.11 \quad 0.0023 *$

When I am inactive my calorie needs do not change

Yes

$19 \quad 17$

No

69

72

Don't Know

$12 \quad 11$

0.50

0.7792

Eating within 45 minutes of a workout is important

Yes

No

\section{5}

Don't Know

Milk is a good source of calcium and vita nin D

Yes

$99 \quad 99$

No

1

Don't Know

0

Whole grain breads are a good source of fiber

Yes

$94 \quad 94$

No

12

Don't Know

5

2

2.13

0.3442

A turkey breast is a good source of lean p rotein

Yes

91

No

1

94

Don't Know

$1-3$

4.27

0.1185

*Based on chi-square analysis, percent response differed significantly at $\mathrm{p}<0.05$

School A= No FT Sports RD

School B= FT Sports RD

Correct Answer (if applicable) 


\section{Men's Football}

As shown in Table 12, 100\% of football athletes surveyed from school A, and $97 \%$ of football athletes surveyed from school B responded that they believe having a nutritious diet would improve their athletic performance. A significantly higher number of football athletes at school B responded that they are aware of how many calories they need to consume every day to promote their best athletic performance $(p<0.05)$. Of football athletes surveyed from school A, 34\% responded that they were aware of their calorie needs, and of football athletes surveyed from school B, 70\% responded that were aware of their calorie needs. A significantly higher number of football athletes surveyed at school B responded that they believe having a sports nutritionist at their University is or would be helpful to them as an athlete $(\mathrm{p}<0.05)$. Of football athletes surveyed at school A, 93\% responded that they believe having a sports nutritionist would be beneficial to them, while $100 \%$ of football athletes surveyed at school B responded that they believe having a sports nutritionist available to them is beneficial. Of football athletes surveyed at school A, 63\% responded correctly that carbohydrates and fats are the main sources of energy for the muscles and 55\% of football athletes surveyed at school B answered correctly. Of football athletes surveyed, 55\% from school A answered correctly, and of football athletes from school B, $61 \%$ answered correctly that protein is not the primary source of energy for muscles. Of football athletes surveyed at school A, 66\% answered correctly, and of football athletes from school B, 70\% answered correctly that protein supplements are not needed in addition to food for muscle growth and development. Of football athletes surveyed at school A, 61\% answered correctly, and of football athletes at school B, 59\% answered correctly that the vast majority of 
supplements sold have not been tested for effectiveness or safety. Of football athletes surveyed at school A, 99\% answered correctly, and of football athletes from school B, 98\% answered correctly that consuming fruits and vegetables every day is important in order to get necessary vitamins and minerals. Of football athletes surveyed at school A, 74\% answered correctly, and of football athletes from school B, 78\% answered correctly that high fat foods should be reduced in the diet. Of football athletes surveyed from school A, 7\% answered correctly, and of football athletes surveyed from school B, 13\% answered correctly that vitamin and mineral supplements do not provide energy to the body. A significantly higher number of football athletes from school A responded that their coaches have encouraged them to either gain or lose weight ( $p<0.05)$. Of football athletes surveyed at school A, 86\% responded that their coaches have encouraged them to either gain or lose weight, while $79 \%$ of football athletes surveyed from school B responded that their coaches have encouraged them to either gain or lose weight. A significantly higher number of football athletes surveyed at school B responded correctly that it is recommended to consume sports drinks during practices lasting longer than 1 hour ( $\mathrm{p}<0.05)$. Of football athletes surveyed at school A, 68\% responded correctly, and of football athletes surveyed at school B, 95\% responded correctly that it is recommended to consume sports drinks during practices lasting longer than 1 hour. Of football athletes surveyed at school A, 68\% responded correctly, and of football athletes surveyed at school B, 67\% responded correctly that sports drinks like Gatorade and Powerade should not be consumed all throughout the day. A significantly higher number of football athletes surveyed at school A responded correctly that during 2-a-days or heavy practice days they should eat more calories $(\mathrm{p}<0.05)$. Of football athletes surveyed at school A, 
$100 \%$ responded correctly, and of football athletes surveyed at school B, 93\% responded correctly that during 2-a-days or heavy practice days they should eat more calories. Of football athletes surveyed at school A, 61\% responded correctly, and of football athletes surveyed at school B, $68 \%$ responded correctly that their calorie needs do change when they are inactive. Of football athletes surveyed from school A, 92\% responded correctly, and of football athletes from school B, 87\% responded correctly that eating within 45 minutes of a workout is important. Of football athletes surveyed from school A, 100\% responded correctly, and of football athletes from school B, 99\% responded correctly that milk is a good source of calcium and vitamin D. Of football athletes surveyed at school A, 92\% responded correctly, and of football athletes from school B, 93\% responded correctly that whole grain breads are a good source of fiber. Of football athletes surveyed from school A, 91\% responded correctly, and from school B, 93\% responded correctly that a turkey breast is a good source of lean protein. 
Table 12. Comparing Nutrition Knowledge of men's football athletes at both School A and School $B(n=222)$

Having a nutritious diet will improve my athletic performance

Yes

No

Don't Know

I am aware of how many calories I need to consume every day to promote my best athletic performance

Yes

No

Don't Know

Having a sports nutritionist at my university is or would be helpful to me as an athlete

Yes

No

Don't Know

Carbohydrates and fats are the main sources of energy for the muscles

$\begin{array}{lll}\text { Yes } & 63 & 55\end{array}$

No $\quad 23 \quad 35$

Don't Know $\quad 15 \quad 10$

Protein is the primary source of energy for the muscles

Yes

$55 \quad 61$

No

$35 \quad 27$

Don't Know

10

1.89

0.3884

Protein supplements are needed in addition to food for muscle growth and development

Yes

No

Don't Know

$66 \quad 70$

$30 \quad 23$

$4 \quad 7$

$1.42 \quad 0.4917$

The vast majority of supplements sold to the general public have been tested for effectiveness or safety

$\begin{array}{lrr}\text { Yes } & 15 & 19\end{array}$

No $\quad 61-59$

Don't Know

$24 \quad 22$

$0.80 \quad 0.6706$

Consuming fruits and vegetables every day is important in order to get necessary vitamins and minerals

$\begin{array}{llll}\text { Yes } & 99 & 98\end{array}$

No 1121

Don't Know $\quad 0 \quad 1$

$1.10 \quad 0.5783$

High-fat foods should be reduced in my diet

Yes

$74 \quad 78$

No

$13 \quad 15$

15

3.03

0.2201

Don't Know

13

7

*Based on chi-square analysis, percent response differed significantly at $\mathrm{p}<0.05$

School A= No FT Sports RD

School B= FT Sports RD

Correct Answer (if applicable) 
Vitamin and mineral supplements provide energy to my body

Yes

\begin{tabular}{|c|c|c|}
\hline $\begin{array}{c}\text { School } \\
\mathbf{A} \\
(\mathrm{n}=88)\end{array}$ & $\begin{array}{c}\text { School } \\
\text { B } \\
(\mathrm{n}=134)\end{array}$ & $X^{2}$ \\
\hline
\end{tabular}

No

$86 \quad 76$

Don't Know

$7 \quad 13$

$7 \quad 11$

$3.63 \quad 0.1626$

My coaches have encouraged me to either gain or lose weight

Yes

$86 \quad 79$

No

Don't Know

$14 \quad 17$

0

$6.82 \quad 0.0330 *$

It is recommended to consume sports drinks during practices lasting longer than 1 hour

Yes

No

Don't Know

Sports drinks like Gatorade and Powerade are better than drinking water and should be consumed all throughout the day

Yes

$19 \quad 25$

No

$68 \quad 67$

Don't Know

0.3992

During 2-a-days or heavy practice days I should eat more calories

Yes
No
Don't Know

Yes

No

Don't Know

$100 \quad 93$

$0 \quad 2$

$0 \quad 4$

$9.28 \quad 0.0097^{*}$

Eating within 45 minutes of a workout is important

Yes

$25 \quad 19$

$61 \quad 68$

$1.15 \quad 0.5639$

$14 \quad 13$

No

Don't Know

$92 \quad 87$

$5 \quad 7$

$3 \quad 5$

Milk is a good source of calcium and vitamin D

Yes

No

Don't Know

$100 \quad 99$

$0 \quad 1$

$0 \quad 0$

Whole grain breads are a good source of fiber

Yes

$92 \quad 93$

No

Don't Know

0

8

3

$5.11 \quad 0.0776$

A turkey breast is a good source of lean protein

Yes

No

Don't Know

$7 \quad 4$

$1.24 \quad 0.5376$

$1.01 \quad 0.3157$

*Based on chi-square analysis, percent response differed significantly at $\mathrm{p}<0.05$

School A= No FT Sports RD

School B= FT Sports RD

Correct Answer (if applicable) 


\section{Men's Wrestling}

As shown in Table 13, 100\% of wrestling athletes surveyed from both school A and school B responded that they believe having a nutritious diet would improve their athletic performance. Of wrestling athletes surveyed from school A, 43\% responded that they were aware of their calorie needs, and of wrestling athletes surveyed from school B, $70 \%$ responded that were aware of their calorie needs. Of wrestling athletes surveyed, $100 \%$ from both school A and school B responded that they believe having a sports nutritionist at their University would be or is helpful to them. Of wrestling athletes surveyed at school A, 79\% responded correctly that carbohydrates and fats are the main sources of energy for the muscles and $50 \%$ of wrestling athletes surveyed at school B answered correctly. Of wrestling athletes surveyed, 21\% from school A answered correctly, and of wrestling athletes from school B, $60 \%$ answered correctly that protein is not the primary source of energy for muscles. Of wrestling athletes surveyed at school A, 29\% answered correctly, and of wrestling athletes from school B, 40\% answered correctly that protein supplements are not needed in addition to food for muscle growth and development. Of wrestling athletes surveyed at school A, 36\% answered correctly, and of wrestling athletes at school B, $47 \%$ answered correctly that the vast majority of supplements sold have not been tested for effectiveness or safety. Of wrestling athletes surveyed at both school A and school B, 100\% answered correctly that consuming fruits and vegetables every day is important in order to get necessary vitamins and minerals. Of wrestling athletes surveyed at school A, 79\% answered correctly, and of wrestling athletes from school B, 80\% answered correctly that high fat foods should be reduced in the diet. A significantly higher number of wrestling athletes from school B responded 
correctly that vitamin and mineral supplements do not provide energy to the body ( $\mathrm{p}$ 0.05). Of wrestling athletes surveyed from school A, 7\% answered correctly, and of wrestling athletes surveyed from school B, 25\% answered correctly that vitamin and mineral supplements do not provide energy to the body. Of wrestling athletes surveyed at school A, 50\% responded that their coaches have encouraged them to either gain or lose weight, while $75 \%$ of wrestling athletes surveyed from school B responded that their coaches have encouraged them to either gain or lose weight. Of wrestling athletes surveyed at school A, 64\% responded correctly, and of wrestling athletes surveyed at school B, 65\% responded correctly that it is recommended to consume sports drinks during practices lasting longer than 1 hour. Of wrestling athletes surveyed at school A, 79\% responded correctly, and of wrestling athletes surveyed at school B, 85\% responded correctly that sports drinks like Gatorade and Powerade should not be consumed all throughout the day. Of wrestling athletes surveyed at school A, 100\% responded correctly, and of wrestling athletes surveyed at school B, 95\% responded correctly that during 2-a-days or heavy practice days they should eat more calories. Of wrestling athletes surveyed at school A, 72\% responded correctly, and of wrestling athletes surveyed at school B, 75\% responded correctly that their calorie needs do change when they are inactive. Of wrestling athletes surveyed from school A, 86\% responded correctly, and of wrestling athletes from school B, 90\% responded correctly that eating within 45 minutes of a workout is important. Of wrestling athletes surveyed from school A, 93\% responded correctly, and of wrestling athletes from school B, 100\% responded correctly that milk is a good source of calcium and vitamin D. Of wrestling athletes surveyed at school A, 100\% responded correctly, and of wrestling athletes from school B, 
$90 \%$ responded correctly that whole grain breads are a good source of fiber. Of wrestling athletes surveyed from school A, 93\% responded correctly, and from school B, 90\% responded correctly that a turkey breast is a good source of lean protein. 
Table 13. Comparing Nutrition Knowledge of wrestling athletes at both School A and School B $(\mathbf{n}=34)$

Having a nutritious diet will improve my athletic

$\begin{array}{cccc}\underset{\substack{\text { School A } \\(n=14)}}{\text { School B }}(\mathbf{n}=20) & X^{2} & \begin{array}{c}\mathbf{p}< \\ \text { value }\end{array}\end{array}$
performance

Yes

No

Don't Know

I am aware of how many calories I need to consume every day to promote my best athletic performance

Yes

No

Don't Know

$\begin{array}{ccc}100 & 100 & \\ 0 & 0 & 0.00 \\ 0 & 0 & \end{array}$

Having a sports nutritionist at my university is or would be helpful to me as an athlete

Yes

No

Don't Know

Carbohydrates and fats are the main sources of energy for the muscles

Yes

No

Don't Know

$14 \quad 35$

Protein is the primary source of energy for the muscles

Yes

$72 \quad 60$

No

21

20

Don't Know

7

1.19

0.5520

Protein supplements are needed in addition to food for muscle growth and development

Yes

No

Don't Know

$64 \quad 45$

$29 \quad 40$

$7 \quad 15$

$1.34 \quad 0.5114$

The vast majority of supplements sold to the general public have been tested for effectiveness or safety

$\begin{array}{lrr}\text { Yes } & 36 & 16\end{array}$

$\begin{array}{lll}\text { No } & 36 & 47\end{array}$

Don't Know

$28 \quad 37$

$1.73 \quad 0.4205$

Consuming fruits and vegetables every day is important in order to get necessary vitamins and minerals

\begin{tabular}{lcccc} 
Yes & 100 & 100 & & \\
No & 0 & 0 & 0.00 & - \\
Don't Know & 0 & 0 & & \\
gh-fat foods should be reduced in my diet & & & & \\
Yes & 79 & 80 & & \\
No & 21 & 15 & 1.25 & 0.5344 \\
Don't Know & 0 & 5 & & \\
\hline
\end{tabular}

*Based on chi-square analysis, percent response differed significantly at $\mathrm{p}<0.05$

School A= No FT Sports RD

School B= FT Sports RD

Correct Answer (if applicable) 
Vitamin and mineral supplements provide energy to my body

Yes

$\underset{\substack{\text { School A } \\(\mathbf{n}=14)}}{\begin{array}{c}\text { School B } \\ (\mathbf{n}=20)\end{array}} \quad \mathrm{X}^{2} \quad \begin{gathered}\mathbf{p}< \\ \text { value }\end{gathered}$

No

$93 \quad 60$

Don't Know

$7 \quad 25$

$0 \quad 15$

My coaches have encouraged me to either gain or lose weight

Yes

$50 \quad 75$

No

Don't Know

It is recommended to consume sports drinks during practices lasting longer than 1 hour

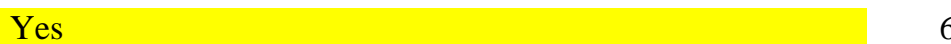

No

$64 \quad 65$

1420

Don't Know

$22 \quad 15$

$0.35 \quad 0.8409$

Sports drinks like Gatorade and Powerade are better than drinking water and should be consumed all throughout the day

Yes

$14-10$

No

85

Don't Know

$79 \quad 85$

0.23

0.8908

During 2-a-days or heavy practice days I should eat more calories

$\begin{array}{lll}\text { Yes } & 100 & 95\end{array}$

No

$0 \quad 5$

1.08

0.2982

Don't Know

$0 \quad 0$

When I am inactive my calorie needs do $\mathrm{n}$ t t change

Yes

$21 \quad 20$

No

72

75

Don't Know

7

0.09

0.9580

Eating within 45 minutes of a workout is important

Yes
No

Don't Know

$86 \quad 90$

$14 \quad 5$

1.87

0.3926

Milk is a good source of calcium and vita in D

Yes

$0 \quad 5$

No

$93 \quad 100$

Don't Know

$7 \quad 0$

$0 \quad 0$

$1.82 \quad 0.1775$

Whole grain breads are a good source of fiber

Yes

$100 \quad 90$

No

$0 \quad 5$

Don't Know

$0 \quad 5$

$2.21 \quad 0.3313$

A turkey breast is a good source of lean pr stein

\begin{tabular}{lcccc} 
Yes & 93 & 90 & & \\
No & 0 & 10 & 3.90 & 0.1420 \\
Don't Know & 7 & 0 & & \\
\hline *Based on chi-square analysis, percent response differed significantly at $\mathrm{p}<0.05$ & & & \\
\hline School A= No FT Sports RD & & & & \\
School B= FT Sports RD & & &
\end{tabular}




\section{Women's Soccer}

As shown in Table 14, 100\% of women's soccer athletes surveyed from both school A and school B responded that they believe having a nutritious diet would improve their athletic performance. Of women's soccer athletes surveyed from school A, $43 \%$ responded that they were aware of their calorie needs, and of women's soccer athletes surveyed from school B, 44\% responded that were aware of their calorie needs. Of women’s soccer athletes surveyed, 92\% from school A and 100\% from school B responded that they believe having a sports nutritionist at their University would be or is helpful to them. Of women’s soccer athletes surveyed at school A, 52\% responded correctly that carbohydrates and fats are the main sources of energy for the muscles and $69 \%$ of women’s soccer athletes surveyed at school B answered correctly. Of women’s soccer athletes surveyed, 17\% from school A answered correctly, and of soccer athletes from school B, 31\% answered correctly that protein is not the primary source of energy for muscles. Of women's soccer athletes surveyed at school A, 57\% answered correctly, and of women's soccer athletes from school B, 56\% answered correctly that protein supplements are not needed in addition to food for muscle growth and development. A significantly higher number of women's soccer athletes surveyed from school B answered correctly that the majority of supplements sold to the general public have not been tested for effectiveness or safety $(\mathrm{p}<0.05)$. Of women's soccer athletes surveyed at school A, 26\% answered correctly, and of women's soccer athletes at school B, 38\% answered correctly that the vast majority of supplements sold have not been tested for effectiveness or safety. Of women's soccer athletes surveyed at both school A and school B, $100 \%$ answered correctly that consuming fruits and vegetables every day is important 
in order to get necessary vitamins and minerals. Of women's soccer athletes surveyed at school A, 69\% answered correctly, and of soccer athletes from school B, 88\% answered correctly that high fat foods should be reduced in the diet. Of women's soccer athletes surveyed from school A, 13\% answered correctly, and of women's soccer athletes surveyed from school B, $12.5 \%$ answered correctly that vitamin and mineral supplements do not provide energy to the body. Of women's soccer athletes surveyed at school A, $22 \%$ responded that their coaches have encouraged them to either gain or lose weight, while $6 \%$ of women's soccer athletes surveyed from school B responded that their coaches have encouraged them to either gain or lose weight. A significantly higher number of women's soccer athletes surveyed from school B answered correctly that it is recommended to consume sports drinks during practices longer than 1 hour $(\mathrm{p}<0.05)$. Of women's soccer athletes surveyed at school A, 52\% responded correctly, and of women's soccer athletes surveyed at school B, 94\% responded correctly that it is recommended to consume sports drinks during practices lasting longer than 1 hour. A significantly higher number of women's soccer athletes from school A answered correctly that sports drinks like Gatorade and Powerade are not better than drinking water and should not be consumed all throughout the day ( $\mathrm{p}<0.05)$. Of women's soccer athletes surveyed at school A, 87\% responded correctly, and of women’s soccer athletes surveyed at school B, 56\% responded correctly that sports drinks like Gatorade and Powerade should not be consumed all throughout the day. Of women's soccer athletes surveyed at school A, 96\% responded correctly, and of women's soccer athletes surveyed at school B, 88\% responded correctly that during 2-a-days or heavy practice days they should eat more calories. Of women's soccer athletes surveyed at school A, 78\% responded correctly, and 
of women's soccer athletes surveyed at school B, 75\% responded correctly that their calorie needs do change when they are inactive. Of women's soccer athletes surveyed from school A, 61\% responded correctly, and of women’s soccer athletes from school B, $88 \%$ responded correctly that eating within 45 minutes of a workout is important. Of women’s soccer athletes surveyed from both school A and school B, 100\% responded correctly that milk is a good source of calcium and vitamin D. Of women's soccer athletes surveyed at school A 96\% responded correctly, and of women’s soccer athletes from school B, 100\% responded correctly that whole grain breads are a good source of fiber. Of women's soccer athletes surveyed from school A, 87\% responded correctly, and from school B, $100 \%$ responded correctly that a turkey breast is a good source of lean protein. 
Table 14. Comparing Nutrition Knowledge of women's soccer athletes at both School A and School B (n=39)

Having a nutritious diet will improve my athletic performance

Yes

No

Don't Know

I am aware of how many calories I need to consume every day to promote my best athletic performance

Yes

No

Don't Know

\begin{tabular}{|c|c|c|c|}
\hline \multicolumn{2}{|c|}{$\%$} & & \\
\hline $\begin{array}{c}\text { School } \\
\text { A } \\
(n=23)\end{array}$ & $\begin{array}{c}\text { School } \\
\text { B } \\
(n=16)\end{array}$ & $X^{2}$ & $\begin{array}{c}\mathbf{p}< \\
\text { value }\end{array}$ \\
\hline
\end{tabular}

$100 \quad 100$

0

$0 \quad 0$

Having a sports nutritionist at my university is or would be helpful to me as an athlete

Yes

No

Don't Know

$43 \quad 44$

$48 \quad 44$

$9 \quad 12$

$0.17 \quad 0.9207$

Carbohydrates and fats are the main sources of energy for the muscles

$\begin{array}{llll}\text { Yes } & 52 & 69\end{array}$

No $\quad 13 \quad 19$

Don't Know $\quad 35 \quad 12$

Protein is the primary source of energy for the muscles

Yes

No

Don't Know

$57 \quad 63$

$17 \quad 31$

$3.20 \quad 0.2016$

Protein supplements are needed in addition to food for muscle growth and development

Yes

No

0

Don't Know

The vast majority of supplements sold to the general public have been tested for effectiveness or safety

Yes

No

Don't Know

Consuming fruits and vegetables every day is important in order to get necessary vitamins and minerals

\begin{tabular}{lcccc} 
Yes & 100 & 100 & & \\
No & 0 & 0 & 0.00 & - \\
Don't Know & 0 & 0 & & \\
gh-fat foods should be reduced in my diet & 69 & 88 & & \\
Yes & 9 & 6 & 2.12 & 0.3463 \\
No & 22 & 6 & & \\
\hline Don't Know & & & \\
\hline
\end{tabular}

*Based on chi-square analysis, percent response differed significantly at $\mathrm{p}<0.05$

School A= No FT Sports RD

School B= FT Sports RD

Correct Answer (if applicable) 
Vitamin and mineral supplements provide energy to my body Yes

No

$\begin{array}{cccc}\underset{c}{\text { School }} & \text { School } & X^{2} & \begin{array}{c}\mathbf{p}< \\ \text { value }\end{array} \\ (\mathbf{n}=23) & \mathbf{B} & & \\ (\mathbf{n}=16) & & \end{array}$

Don't Know

$61 \quad 75$

$13 \quad 12.5$

$26 \quad 12.5$

My coaches have encouraged me to either gain or lose weight

Yes

No

$22 \quad 6$

Don't Know

78

88

$0 \quad 6$

It is recommended to consume sports drinks during practices lasting longer than 1 hour

Yes

No

Don't Know

Sports drinks like Gatorade and Powerade are better than drinking water and should be consumed all throughout the day

Yes

No

Don't Know

During 2-a-days or heavy practice days I should eat more calories

Yes

No

Don't Know

When I am inactive my calorie needs do not change

Yes

No

Don't Know

0

$9.43 \quad 0.0090$ *

6

$4 \quad 38$

$87 \quad 56$

96

$7.320 .0258 *$

6

$96 \quad 88$

$0 \quad 6$

$1.92 \quad 0.3837$

46

$4 \quad 12.5$

$78 \quad 75$

$18 \quad 12.5$

Eating within 45 minutes of a workout is important

Yes

$61 \quad 88$

No

$13 \quad 0$

$4.99 \quad 0.0826$

Don't Know

Milk is a good source of calcium and vitamin D

Yes

$100 \quad 100$

No

$0 \quad 0$

$0.96 \quad 0.6175$

Don't Know

$0 \quad 0$

Whole grain breads are a good source of fiber

Yes

No

Don't Know

$96 \quad 100$

$4 \quad 0$

$1.07 \quad 0.3000$

A turkey breast is a good source of lean protein

Yes

87

No

13

100

Don't Know

0

$\mathrm{p}<0.05$

*Based on chi-square analysis, percent response differed significantly at $\mathrm{p}<0.05$

School A= No FT Sports RD

School B= FT Sports RD

Correct Answer (if applicable) 


\section{Women's Swimming/Diving}

As shown in Table 15, 100\% of women's swimming/diving athletes surveyed from both school A and school B responded that they believe having a nutritious diet would improve their athletic performance. A significantly higher numbeof women’s swimming and diving athletes from school B responded that they are aware of how many calories they need to consume every day in order to promote their best athletic performance $(\mathrm{p}<0.05)$. Of women's swimming/diving athletes surveyed from school A, $17 \%$ responded that they were aware of their calorie needs, and of swimming/diving athletes surveyed from school B, 75\% responded that were aware of their calorie needs. Of women’s swimming/diving athletes surveyed, 92\% from school A and 95\% from school B responded that they believe having a sports nutritionist at their University would be or is helpful to them. Of women's swimming/diving athletes surveyed at school A, $42 \%$ responded correctly and 55\% of women’s swimming/diving athletes surveyed from school B answered correctly that carbohydrates and fats are the main sources of energy for the muscles. Of women’s swimming/diving athletes surveyed, 17\% from school A answered correctly, and of swimming/diving athletes from school B, 55\% answered correctly that protein is not the primary source of energy for muscles. Of women’s swimming/diving athletes surveyed at school A, 58\% answered correctly, and of women's swimming/diving athletes from school B, 65\% answered correctly that protein supplements are not needed in addition to food for muscle growth and development. Of women’s swimming/diving athletes surveyed at school A, 50\% answered correctly, and of women's swimming/diving athletes at school B, 45\% answered correctly that the vast majority of supplements sold have not been tested for effectiveness or safety. Of 
women’s swimming/diving athletes surveyed at school A, 92\% answered correctly, and of women's swimming/diving athletes surveyed from school B, 100\% answered correctly that consuming fruits and vegetables every day is important in order to get necessary vitamins and minerals. Of women's swimming/diving athletes surveyed at school A, 92\% answered correctly, and of swimming/diving athletes from school B, 75\% answered correctly that high fat foods should be reduced in the diet. Of women's swimming/diving athletes surveyed from school A, 17\% answered correctly, and of women’s swimming/diving athletes surveyed from school B, 35\% answered correctly that vitamin and mineral supplements do not provide energy to the body. Of women’s swimming/diving athletes surveyed at school A, 50\% responded that their coaches have encouraged them to either gain or lose weight, while $25 \%$ of women’s swimming/diving athletes surveyed from school B responded that their coaches have encouraged them to either gain or lose weight. Of women's swimming/diving athletes surveyed at school A, 83\% responded correctly, and of women's swimming/diving athletes surveyed at school $\mathrm{B}, \mathbf{8 5 \%}$ responded correctly that it is recommended to consume sports drinks during practices lasting longer than 1 hour. Of women’s swimming/diving athletes surveyed at school A, 83\% responded correctly, and of women’s swimming/diving athletes surveyed at school B, 85\% responded correctly that sports drinks like Gatorade and Powerade should not be consumed all throughout the day. Of women's swimming/diving athletes surveyed at school A, 100\% responded correctly, and of women's swimming/diving athletes surveyed at school B, 85\% responded correctly that during 2-a-days or heavy practice days they should eat more calories. Of women's swimming/diving athletes surveyed at school A, 100\% responded correctly, and of women’s swimming/diving 
athletes surveyed at school B, 95\% responded correctly that their calorie needs do change when they are inactive. Of women's swimming/diving athletes surveyed from school A, 100\% responded correctly, and of women's swimming/diving athletes from school B, $85 \%$ responded correctly that eating within 45 minutes of a workout is important. Of women's swimming/diving athletes surveyed from both school A and school B, 100\% responded correctly that milk is a good source of calcium and vitamin D. Of women's swimming/diving athletes surveyed at both school A and school B, 100\% responded correctly that whole grain breads are a good source of fiber. Of women's swimming/diving athletes surveyed from school A, 92\% responded correctly, and from school B, 100\% responded correctly that a turkey breast is a good source of lean protein. 
Table 15. Comparing Nutrition Knowledge of women's swimming/diving athletes at both School A and School B (n=32)

Having a nutritious diet will improve my athletic performance

Yes

No

Don't Know

I am aware of how many calories I need to consume every day to promote my best athletic performance

Yes

No

Don't Know

Having a sports nutritionist at my university is or would be helpful to me as an athlete

Yes

No

Don't Know

\begin{tabular}{|c|c|c|c|}
\hline \multicolumn{2}{|c|}{$\%$} & \multirow[b]{2}{*}{$\mathbf{X}^{2}$} & \multirow[b]{2}{*}{$\begin{array}{c}\mathbf{p}< \\
\text { value }\end{array}$} \\
\hline $\begin{array}{c}\text { School } \\
\text { A } \\
(n=12)\end{array}$ & $\begin{array}{c}\text { School } \\
\text { B } \\
(n=20)\end{array}$ & & \\
\hline
\end{tabular}

$\begin{array}{ccc}100 & 100 & \\ 0 & 0 & 0.00 \\ 0 & 0 & \end{array}$

Carbohydrates and fats are the main sources of energy for the muscles

Yes

Don't Know

$17 \quad 75$

$75 \quad 15$

$8 \quad 10$

$12.71 \quad 0.0017^{*}$

rotein is the primary source of energy for the muscles

Yes

No

Don't Know

$92 \quad 95$

$8 \quad 5$

$0 \quad 0$

$0.11 \quad 0.7378$

$42 \quad 55$

$8 \quad 20$

$50 \quad 25$

$2.30 \quad 0.3162$

rotein supplements are needed in addition to food for muscle growth and development

Yes

$50 \quad 30$

$17 \quad 55$

$33 \quad 15$

$4.98 \quad 0.0829$

No

Don't Know

$25 \quad 10$

$58 \quad 65$

$17 \quad 25$

The vast majority of supplements sold to the general public have been tested for effectiveness or safety

Yes

No

Don't Know

Consuming fruits and vegetables every day is important in order to get necessary vitamins and minerals

\begin{tabular}{lc|ccc} 
Yes & 92 & 100 & & \\
No & 8 & 0 & 2.02 & 0.1557 \\
Don't Know & 0 & 0 & & \\
gh-fat foods should be reduced in my diet & 92 & 75 & & \\
Yes & 0 & 20 & 4.14 & 0.1261 \\
No & 8 & 5 & & \\
\hline Don't Know
\end{tabular}

*Based on chi-square analysis, percent response differed significantly at $\mathrm{p}<0.05$

School A= No FT Sports RD

School B= FT Sports RD

Correct Answer (if applicable) 
Vitamin and mineral supplements provide energy to my body

\begin{tabular}{|c|c|c|}
\hline & & $\mathrm{X}^{2}$ \\
\hline $\begin{array}{c}\text { School } \\
\text { A } \\
(n=12)\end{array}$ & $\begin{array}{c}\text { School } \\
\text { B } \\
(\mathbf{n}=20)\end{array}$ & \\
\hline
\end{tabular}

No
Don't Know

$50 \quad 50$

$17 \quad 35$

$33 \quad 15$

$2.08 \quad 0.3544$

My coaches have encouraged me to either gain or lose weight

Yes

$50 \quad 25$

No

$50 \quad 75$

Don't Know

0

2.06

0.1518

It is recommended to consume sports drinks during practices lasting longer than 1 hour

Yes

$83 \quad 85$

No

$17 \quad 10$

Don't Know

$0 \quad 5$

Sports drinks like Gatorade and Powerade are better than drinking water and should be consumed all throughout the day

Yes

No

$0 \quad 5$

$83 \quad 85$

Don't Know

$17 \quad 10$

During 2-a-days or heavy practice days I should eat more calories

$\begin{array}{lll}\text { Yes } & 100 & 85\end{array}$

No $\quad 0 \quad 10$

Don't Know $\quad 0 \quad 5$

When I am inactive my calorie needs do not change

Yes

No

0

Don't Know

100

0.96

0.3274

Eating within 45 minutes of a workout is important

$\begin{array}{lll}\text { Yes } & 100 & 85\end{array}$

No $\quad 0 \quad 10$

Don't Know $\quad 0 \quad 5$

Milk is a good source of calcium and vita nin D

$\begin{array}{lrl}\text { Yes } & 100 & 100\end{array}$

No $\quad 00$

Don't Know $\quad 0 \quad 0$

Whole grain breads are a good source of fiber

$\begin{array}{lll}\text { Yes } & 100 & 100\end{array}$

No 100

Don't Know

$0 \quad 0$

A turkey breast is a good source of lean p rotein

Yes

$92 \quad 100$

No

$0 \quad 0$

Don't Know

$8 \quad 0$

$3.00 \quad 0.0007$

5

$1.20 \quad 0.5486$

$1.20 \quad 0.5486$

$3.00 \quad 0.2227$

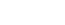

*Based on chi-square analysis, percent response differed significantly at $\mathrm{p}<0.05$

School A= No FT Sports RD

School B= FT Sports RD

Correct Answer (if applicable) 


\section{Self-Efficacy of the Athletes}

All athletes surveyed were asked to answer 5 questions assessing how confident they were in making certain nutrition decisions. They responded with numbers on a scale of 1 to 10 , with 1 being the least confident and 10 being the most confident. As shown in Table 16, of all athletes surveyed, athletes from school B were significantly more confident in their abilities to eat a healthy snack before and after a workout $(\mathrm{p}<0.05)$. Regarding how certain they were they could eat a healthy snack before and after a workout, of all athletes surveyed from school A the mean confidence rating was 7.66, while the mean confidence rating of all athletes surveyed from school B was 8.27. Of all athletes surveyed, athletes from school B were significantly more confident in their abilities to eat a nutritious, balanced diet $(\mathrm{p}<0.05)$. Regarding how certain they were they could eat a nutritious, balanced diet, of all athletes surveyed from school A the mean confidence rating was 6.89 , while the mean confidence rating of all athletes surveyed from school B was 7.85. Of all athletes surveyed, athletes from school B were significantly more confident in their abilities to eat the correct amount of calories each day $(\mathrm{p}<0.05)$. Regarding how certain they were they could eat the correct amount of calories each day, of all athletes surveyed from school A the mean confidence rating was 6.70, while the mean confidence rating of all athletes surveyed from school B was 7.68. Of all athletes surveyed, athletes from school B were significantly more confident in their abilities to maintain a healthy weight with diet and exercise $(\mathrm{p}<0.05)$. Regarding how certain they were they could maintain a healthy weight with diet and exercise, of all athletes surveyed from school A the mean confidence rating was 7.96, while the mean confidence rating of all athletes surveyed from school B was 8.56. Of all athletes 
surveyed, athletes from school B were significantly more confident in their abilities to keep hydrated before, during, and after practice and competition $(\mathrm{p}<0.05)$. Regarding how certain they were they could keep hydrated before, during, and after practice and competition, of all athletes surveyed from school A the mean confidence rating was 8.32, while the mean confidence rating of all athletes surveyed from school B was 8.70.

Table 16. Comparison of Self-efficacy of all athletes from School A and School B $(\mathrm{n}=327)$

\begin{tabular}{|c|c|c|c|}
\hline $\begin{array}{l}\text { On a scale of 1-10, how certain are you that } \\
\text { you can... }\end{array}$ & Mean +/- SD & F Ratio & Prob $>$ F \\
\hline \multicolumn{4}{|l|}{ Eat a healthy snack pre and post workout } \\
\hline School A $(n=137)$ & $7.66+/-0.17$ & \multirow{2}{*}{7.01} & \multirow{2}{*}{$0.0085^{*}$} \\
\hline School B (n=190) & $8.27+/-0.15$ & & \\
\hline \multicolumn{4}{|l|}{ Eat a nutritious, balanced diet } \\
\hline School A (n=137) & $6.89+/-0.16$ & \multirow{2}{*}{21.46} & \multirow{2}{*}{$<0.0001^{*}$} \\
\hline School B $(n=190)$ & $7.85+/-0.13$ & & \\
\hline \multicolumn{4}{|l|}{ Eat the correct amount of calories each day } \\
\hline School A (n=137) & $6.70+/-0.16$ & 21.88 & $<0.0001^{*}$ \\
\hline \multicolumn{4}{|l|}{$\begin{array}{l}\text { Maintain a healthy weight with diet and } \\
\text { exercise }\end{array}$} \\
\hline School A $(n=137)$ & $7.96+/-0.14$ & 9.92 & $0.0018^{*}$ \\
\hline \multicolumn{4}{|l|}{$\begin{array}{l}\text { Keep hydrated before, during and after } \\
\text { practice and competition }\end{array}$} \\
\hline School A (n=137) & $8.32+/-0.15$ & \multirow{2}{*}{3.90} & \multirow{2}{*}{$0.0491 *$} \\
\hline School B $(n=190)$ & $8.70+/-0.12$ & & \\
\hline
\end{tabular}

Men's Football

All men's football athletes surveyed, at both Universities, were asked to answer 5 questions assessing how confident they were in making certain nutrition decisions. They responded with numbers on a scale of 1 to 10 , with 1 being the least confident and 10 
being the most confident. As shown in Table 17, of football athletes surveyed, athletes from school B were significantly more confident in their abilities to eat a healthy snack before and after a workout $(\mathrm{p}<0.05)$. Regarding how certain they were they could eat a healthy snack before and after a workout, of football athletes surveyed from school A the mean confidence rating was 7.94, while the mean confidence rating of football athletes surveyed from school B was 8.54. Of football athletes surveyed, athletes from school B were significantly more confident in their abilities to eat a nutritious, balanced diet $(\mathrm{p}<$ 0.05). Regarding how certain they were they could eat a nutritious, balanced diet, of football athletes surveyed from school A the mean confidence rating was 6.82, while the mean confidence rating of football athletes surveyed from school B was 7.89. Of football athletes surveyed, athletes from school B were significantly more confident in their abilities to eat the correct amount of calories each day $(\mathrm{p}<0.05)$. Regarding how certain they were they could eat the correct amount of calories each day, of football athletes surveyed from school A the mean confidence rating was 6.73, while the mean confidence rating of football athletes surveyed from school B was 7.65. Of football athletes surveyed, athletes from school B were significantly more confident in their abilities to maintain a healthy weight with diet and exercise $(\mathrm{p}<0.05)$. Regarding how certain they were they could maintain a healthy weight with diet and exercise, of football athletes surveyed from school A the mean confidence rating was 7.94, while the mean confidence rating of football athletes surveyed from school B was 8.71. Of football athletes surveyed, athletes from school B were significantly more confident in their abilities to keep hydrated before, during, and after practice and competition $(\mathrm{p}<0.05)$. Regarding how certain they were they could keep hydrated before, during, and after practice and 
competition, of football athletes surveyed from school A the mean confidence rating was 8.33, while the mean confidence rating of football athletes surveyed from school B was 9.01 .

Table 17. Comparison of self-efficacy of football athletes from school A and school B $(\mathrm{n}=222)$

\begin{tabular}{|c|c|c|c|}
\hline $\begin{array}{l}\text { On a scale of } 1-10 \text {, how certain are you } \\
\text { that you can... }\end{array}$ & Mean +/- SD & $\begin{array}{c}\mathbf{F} \\
\text { Ratio }\end{array}$ & Prob $>$ F \\
\hline \multicolumn{4}{|l|}{ Eat a healthy snack pre and post workout } \\
\hline $\begin{array}{l}\text { School A }(n=88) \\
\text { School B }(n=134)\end{array}$ & $\begin{array}{l}7.94+/-0.20 \\
8.54+/-0.17\end{array}$ & 5.11 & $0.0248 *$ \\
\hline \multicolumn{4}{|l|}{ Eat a nutritious, balanced diet } \\
\hline $\begin{array}{l}\text { School A }(n=88) \\
\text { School B }(n=134)\end{array}$ & $\begin{array}{l}6.82+/-0.20 \\
7.89+/-0.16\end{array}$ & 17.92 & $<0.0001^{*}$ \\
\hline \multicolumn{4}{|l|}{ Eat the correct amount of calories each day } \\
\hline $\begin{array}{l}\text { School A }(n=88) \\
\text { School B }(n=134)\end{array}$ & $\begin{array}{l}6.73+/-0.20 \\
7.65+/-0.16\end{array}$ & 12.51 & $0.0005^{*}$ \\
\hline \multicolumn{4}{|l|}{$\begin{array}{l}\text { Maintain a healthy weight with diet and } \\
\text { exercise }\end{array}$} \\
\hline $\begin{array}{l}\text { School A }(n=88) \\
\text { School B }(n=134)\end{array}$ & $\begin{array}{l}7.94+/-0.17 \\
8.71+/-0.14\end{array}$ & 11.57 & $0.0008 *$ \\
\hline \multicolumn{4}{|l|}{$\begin{array}{l}\text { Keep hydrated before, during and after } \\
\text { practice and competition }\end{array}$} \\
\hline $\begin{array}{l}\text { School A }(n=88) \\
\text { School B }(n=134)\end{array}$ & $\begin{array}{l}8.33+/-0.16 \\
9.01+/-0.13 \\
\end{array}$ & 10.31 & $0.0015^{*}$ \\
\hline
\end{tabular}

*Based on one-way ANOVA mean response differed significantly at $\mathrm{p}<0.05$

School A= No FT Sports RD

School B= FT Sports RD

Men's Wrestling

All men's wrestling athletes surveyed, at both Universities, were asked to answer 5 questions assessing how confident they were in making certain nutrition decisions. They responded with numbers on a scale of 1 to 10, with 1 being the least confident and 10 being the most confident. As shown in Table 18, regarding how certain they were they 
could eat a healthy snack before and after a workout, of wrestling athletes surveyed from school A the mean confidence rating was 8.00 , while the mean confidence rating of wrestling athletes surveyed from school B was 7.75. Regarding how certain they were they could eat a nutritious, balanced diet, of wrestling athletes surveyed from school A the mean confidence rating was 7.64, while the mean confidence rating of wrestling athletes surveyed from school B was 8.10. Regarding how certain they were they could eat the correct amount of calories each day, of wrestling athletes surveyed from school A the mean confidence rating was 7.64, while the mean confidence rating of wrestling athletes surveyed from school B was 8.65. Regarding how certain they were they could maintain a healthy weight with diet and exercise, of wrestling athletes surveyed from school A the mean confidence rating was 8.71, while the mean confidence rating of wrestling athletes surveyed from school B was 8.45. Regarding how certain they were they could keep hydrated before, during, and after practice and competition, of wrestling athletes surveyed from school A the mean confidence rating was 8.07, while the mean confidence rating of wrestling athletes surveyed from school B was 8.10. 
Table 18. Comparison of self-efficacy of men's wrestling athletes from school A and school B $(\mathbf{n}=34)$

\begin{tabular}{|c|c|c|c|}
\hline $\begin{array}{l}\text { On a scale of 1-10, how certain are you that } \\
\text { you can... }\end{array}$ & Mean +/- SD & $\begin{array}{c}\text { F } \\
\text { Ratio }\end{array}$ & Prob $>$ F \\
\hline \multicolumn{4}{|l|}{ Eat a healthy snack pre and post workout } \\
\hline School A $(n=14)$ & $8.00+/-0.49$ & \multirow{2}{*}{0.1501} & \multirow{2}{*}{0.7010} \\
\hline School B $(n=20)$ & $7.75+/-0.41$ & & \\
\hline \multicolumn{4}{|l|}{ Eat a nutritious, balanced diet } \\
\hline School A $(n=14)$ & $7.64+/-0.41$ & \multirow{2}{*}{0.7151} & \multirow{2}{*}{0.4040} \\
\hline School B $(n=20)$ & $8.10+/-0.35$ & & \\
\hline \multicolumn{4}{|l|}{ Eat the correct amount of calories each day } \\
\hline School A $(n=14)$ & $7.64+/-0.44$ & \multirow{2}{*}{3.1168} & \multirow{2}{*}{0.0870} \\
\hline School B $(n=20)$ & $8.65+/-0.37$ & & \\
\hline \multicolumn{4}{|l|}{$\begin{array}{l}\text { Maintain a healthy weight with diet and } \\
\text { exercise }\end{array}$} \\
\hline School A $(n=14)$ & $8.71+/-0.38$ & \multirow{2}{*}{0.2797} & \multirow{2}{*}{0.6005} \\
\hline School B (n=20) & $8.45+/-0.32$ & & \\
\hline \multicolumn{4}{|l|}{$\begin{array}{l}\text { Keep hydrated before, during and after practice } \\
\text { and competition }\end{array}$} \\
\hline School A $(n=14)$ & $8.07+/-0.45$ & \multirow{2}{*}{0.0024} & \multirow{2}{*}{0.9615} \\
\hline School B $(n=20)$ & $8.10+/-0.38$ & & \\
\hline
\end{tabular}

*Based on one-way ANOVA mean response differed significantly at $\mathrm{p}<0.05$

School A= No FT Sports RD

School B= FT Sports RD

Women's Soccer

All women's soccer athletes surveyed, at both Universities, were asked to answer 5 questions assessing how confident they were in making certain nutrition decisions. They responded with numbers on a scale of 1 to 10 , with 1 being the least confident and 10 being the most confident. As shown in Table 19, regarding how certain they were they could eat a healthy snack before and after a workout, of soccer athletes surveyed from school A the mean confidence rating was 6.82, while the mean confidence rating of soccer athletes surveyed from school B was 8.19. Regarding how certain they were they could eat a nutritious, balanced diet, of soccer athletes surveyed from school A the mean 
confidence rating was 6.83 , while the mean confidence rating of soccer athletes surveyed from school B was 7.38. Regarding how certain they were they could eat the correct amount of calories each day, of soccer athletes surveyed from school A the mean confidence rating was 6.30 , while the mean confidence rating of soccer athletes surveyed from school B was 7.25. Regarding how certain they were they could maintain a healthy weight with diet and exercise, of soccer athletes surveyed from school A the mean confidence rating was 7.65, while the mean confidence rating of soccer athletes surveyed from school B was 8.69. Regarding how certain they were they could keep hydrated before, during, and after practice and competition, of soccer athletes surveyed from school A the mean confidence rating was 8.30, while the mean confidence rating of soccer athletes surveyed from school B was 8.94.

Table 19. Comparison of self-efficacy of women's soccer athletes from school A and school B (n=39)

\begin{tabular}{|c|c|c|c|}
\hline $\begin{array}{l}\text { On a scale of 1-10, how certain are you that } \\
\text { you can... }\end{array}$ & Mean +/- SD & F Ratio & Prob $>$ F \\
\hline \multicolumn{4}{|l|}{ Eat a healthy snack pre and post workout } \\
\hline $\begin{array}{l}\text { School A }(n=23) \\
\text { school B }(n=16)\end{array}$ & $\begin{array}{l}6.83+/-0.45 \\
8.19+/-0.54\end{array}$ & 3.68 & 0.0627 \\
\hline \multicolumn{4}{|l|}{ Eat a nutritious, balanced diet } \\
\hline $\begin{array}{l}\text { School A }(n=23) \\
\text { School B }(n=16)\end{array}$ & $\begin{array}{l}6.83+/-0.44 \\
7.38+/-0.53\end{array}$ & 0.64 & 0.4298 \\
\hline \multicolumn{4}{|l|}{ Eat the correct amount of calories each day } \\
\hline $\begin{array}{l}\text { School A }(n=23) \\
\text { School B }(n=16)\end{array}$ & $\begin{array}{l}6.30+/-0.37 \\
7.25+/-0.44\end{array}$ & 2.69 & 0.1092 \\
\hline \multicolumn{4}{|l|}{ Maintain a healthy weight with diet and exercise } \\
\hline $\begin{array}{l}\text { School A }(n=23) \\
\text { School B }(n=16)\end{array}$ & $\begin{array}{l}7.65+/-0.34 \\
8.69+/-0.41\end{array}$ & 3.72 & 0.0615 \\
\hline \multicolumn{4}{|l|}{$\begin{array}{l}\text { Keep hydrated before, during and after practice } \\
\text { and competition }\end{array}$} \\
\hline $\begin{array}{l}\text { School A }(n=23) \\
\text { School B }(n=16)\end{array}$ & $\begin{array}{l}8.30+/-3.78 \\
8.94+/-2.81\end{array}$ & 1.35 & 0.2530 \\
\hline
\end{tabular}


Women's Swimming/Diving

All women’s swimming/diving athletes surveyed, at both Universities, were asked to answer 5 questions assessing how confident they were in making certain nutrition decisions. They responded with numbers on a scale of 1 to 10 , with 1 being the least confident and 10 being the most confident. As shown in Table 20, regarding how certain they were they could eat a healthy snack before and after a workout, of swimming/diving athletes surveyed from school A the mean confidence rating was 6.83, while the mean confidence rating of swimming/diving athletes surveyed from school B was 7.05. Regarding how certain they were they could eat a nutritious, balanced diet, of swimming/diving athletes surveyed from school A the mean confidence rating was 6.66, while the mean confidence rating of swimming/diving athletes surveyed from school B was 7.70. Regarding how certain they were they could eat the correct amount of calories each day, of swimming/diving athletes surveyed from school A the mean confidence rating was 6.17, while the mean confidence rating of swimming/diving athletes surveyed from school B was 7.30. Regarding how certain they were they could maintain a healthy weight with diet and exercise, of swimming/diving athletes surveyed from school A the mean confidence rating was 7.83, while the mean confidence rating of swimming/diving athletes surveyed from school B was 7.55. Regarding how certain they were they could keep hydrated before, during, and after practice and competition, of swimming/diving athletes surveyed from school A the mean confidence rating was 8.58, while the mean confidence rating of swimming/diving athletes surveyed from school B was 7.00. 
Table 20. Comparison of self-efficacy of women's swimming/diving athletes from school $A$ and school $B(n=32)$

On a scale of 1-10, how certain are you that you can...

Eat a healthy snack pre and post workout

School A $(n=12)$

School B $(n=20)$

Eat a nutritious, balanced diet

School A ( $\mathrm{n}=12)$

School B $(n=20)$

Eat the correct amount of calories each day

School A ( $n=12)$

School B $(n=20)$

Maintain a healthy weight with diet and exercise

School A $(n=12)$

School B ( $\mathrm{n}=20)$

Keep hydrated before, during and after practice and competition

School A $(n=12)$

School B $(n=20)$

$7.00+/-0.48$
$8.58+/-0.62$

Mean +/- SD $\quad$ F Ratio $\quad$ Prob $>$ F

$6.83+/-0.70$

$7.05+/-0.54$

$0.06 \quad 0.8085$

$6.67+/-0.53$

$7.70+/-0.41$

2.38

0.1332

$6.17+/-0.54$

$7.30+/-0.42$

2.78

0.1057

$7.83+/-0.60$

$7.55+/-0.46$

0.14

0.7105

4.12

0.0513

*Based on one-way ANOVA mean response differed significantly at $\mathrm{p}<0.05$

School A= No FT Sports RD

School B= FT Sports RD 


\section{DISCUSSION}

It has been suggested by many researchers that sports nutrition departments,

which include a sports registered dietitian, could be beneficial for college athletes. ${ }^{1-4,5,6,7}$

Although this has been suggested, very minimal research has actually been done to determine the importance of such a department and if it makes a difference in the nutrition knowledge, self-efficacy, and nutrient intake behaviors of NCAA Division I

student athletes. ${ }^{1}$ Some studies have been done assessing the nutrition knowledge and intake behaviors of such athletes, but the majority of them are out-of-date or on such a specific group of athletes it is difficult to generalize the results to Division I college athletes in general.

\section{Sources of Nutrition Counseling and Information:}

Research has shown that male and female athletes receive most of their nutrition knowledge from classes, family, magazines and newspapers, friends, and strength and conditioning coaches and athletic trainers. ${ }^{3,8}$ Research has also shown that one of the places athletes get the least amount of nutrition information is Registered Dietitians. ${ }^{3,8}$ The results from this study agree with results from these previous studies, when considering student athletes from school A, the University without a Sports Nutrition Department and thus a full time sports RD. Of all athletes surveyed from school A in the current study, 28\% responded that they get their nutrition information from a strength and conditioning coach, 23\% said from family, 15\% from a Registered Dietitian, and 26\% said from the internet. In comparison, regarding sources of nutrition information, $43 \%$ of athletes from school B in the current study indicated strength and conditioning coaches as 
a source, $26 \%$ indicated teammates a source, $28 \%$ indicated the internet as a source, and 24\% indicated a Registered Dietitian as a source. There was a significant difference in the amount of student athletes from school A and B who indicated they get nutrition information from a Registered Dietitian, with more athletes from school B indicating this as a source for information $(\mathrm{p}<0.05)$. Football players from school $\mathrm{A}$ in the study identified strength and conditioning coaches and the internet as the two places they get most of their nutrition information, while football athletes from school B identified teammates, strength and conditioning coaches, the internet, athletic trainers, and registered dietitians as their largest sources for nutrition information. Taking this into consideration, when a Registered Dietitian is on campus full-time, a significant amount more athletes receive their nutrition information from this credible source $(\mathrm{p}<0.05)$. Strength and conditioning coaches were consistently identified in this study, as in previous studies, as a source a large number of athletes look to for nutrition information. ${ }^{3,8}$ Interestingly, most strength and conditioning coaches, although they may be interested in nutrition, do not have formal nutrition education. Therefore, this is not the most reliable source of nutrition information for athletes. There were not, however, significant differences in the numbers of athletes getting nutrition information from Registered Dietitians, among the other three teams in this study. Taking these results into consideration, the biggest differences are seen where the greatest efforts are placed. At school B, there is one full-time sports RD dedicating the majority of their time specifically to football. Therefore, these athletes receive the most one-on-one counseling and team education of any athlete at the University. 
When taking all athletes into consideration, a higher percentage from school B indicated that they actually seek out nutrition information. If they indicated they did not actively seek out this information, the majority, 15\% indicated it was because it is not a major concern to them. From school A, a significant amount less of athletes, $40 \%$, stated they actively seek out or read nutrition information. Of the $58 \%$ of these athletes at school A who stated they do not do this, the majority, 36\% indicated they didn't because it is not a major concern to them. Football athletes responded much in the same way, 70\% from school B responded they actively seek out nutrition information, while 34\% from school A responded that they do this. Again, similar to sources of nutrition information, with the other three sports, men’s wrestling, women’s soccer, and women’s swimming/diving, significant differences were not found as to if the athletes actively seek out or read nutrition information. This is most likely due to one of two reasons; the athletes from school $\mathrm{A}$, in these three sports find it more important to seek out nutrition information than the football athletes from school A, or the athletes in these sports from school B have not been educated as much as football athletes to understand how important it is to their health and performance to seek this information out.

\section{Nutrition Knowledge of the Athletes}

Research has demonstrated the importance of accurate nutrition knowledge and has shown that adequate nutrition knowledge can lead to better intake decisions, ultimately assisting in optimal athletic performance. ${ }^{4}$ When an athlete is properly informed to make good nutrition decisions, they can then take ownership over their diet, during college, and also after leaving college. When an athlete's diet is lacking in certain important nutrients or is not balanced, it is usually due to the fact that they are not well- 
informed to make the correct nutrition decisions. ${ }^{2,9}$ The most recent study done looking at nutrition knowledge of college football players, found that only small percentages could properly identify the proper carbohydrate, protein, and fat intake. ${ }^{3}$ This current study, when considering both athletes from school A and B found the majority of athletes to be fairly knowledgeable. However, some differences were found between school A and $\mathrm{B}$, showing that the athletes with access to a full time Registered-Dietitian, were more knowledgeable in these specific areas.

When considering athletes as a whole, from both school A and school B, almost all athletes identified that they believe having a nutritious diet will improve their athletic performance. Athletes from school B were more aware of how many calories they need to consume everyday in order to promote their best athletic performance. Also, a significant amount higher number of athletes from school B identified that having a Sports Nutritionist at their University is helpful to them as an athlete. This outcome shows that athletes with access to the Registered Dietitian on a daily basis have a better idea about how important nutrition is to their athletic performance and also understand how important it is to have access to someone who can assist them with this. It is interesting to note that the place where the largest, most significant differences were seen in the nutrition knowledge of athletes as a whole were regarding hydration and how many calories they should be eating. Athletes from school B were more educated on hydration, correctly identifying when they should consume Sports Drinks. Interestingly, athletes from school A were more knowledgeable about their calorie needs changing when they have 2-a-days or heavy practice days. 
In general, similar differences were seen among football athletes from both Universities as were seen among athletes from the two Universities as a whole. Football athletes from school B were significantly more aware of how many calories they needed to consume and a significant amount more believed having a Sports Nutritionist at their University is helpful to them. A significant number more of football athletes from school A identified that their coaches have encouraged them to either lose or gain weight. This is also likely to occur when coaches and strength and conditioning coaches, who do not have formal nutrition education, are doing the majority of the nutrition education. It is likely coaches without access to a Sports RD perceive certain athletes as overweight or underweight when in fact they may not be. Football athletes from school A were more knowledgeable about needing to eat more calories on days of heavy practices.

When taking wrestling athletes into consideration, there were not many significant differences found regarding nutrition knowledge. The one significant difference which was found between the schools was not found with other teams. Wrestling athletes from school B were significantly more knowledgeable about vitamin and mineral supplements not providing energy to the body. Again, as with sources of nutrition information and counseling, not as many significant differences were found as expected, likely due to either more wrestlers at school A seeking out the contracted Registered Dietitian or wrestlers at school B having less contact with the full time Registered Dietitian on staff. Again, suggesting that while it is important to have a Registered Dietitian on staff; it is just as important that they place equal effort with each team. Again, based on this study, where the effort is placed, the biggest differences are seen. 
Women's soccer athletes from school B were more knowledgeable on supplements not being tested for effectiveness or safety and when to drink Sports Drinks. However, soccer athletes from school A were more knowledgeable on the importance of drinking water, not sports drinks throughout the day. While there were differences in nutrition knowledge, there were fewer significant differences than were found with football, suggesting, again, that where the effort is placed is where the athletes are most knowledgeable and most prepared to make better nutrition decisions.

Women’s swimming/diving athletes from school B were more aware of their calorie needs, but no other significant differences were found. Among each team, in general, a higher percentage of athletes from school B answered each question correctly, but not all of these differences were significant.

\section{Self-efficacy of the Athletes}

As a whole, athletes from school B were more confident in making certain nutrition decisions than the athletes from school A. The athletes from school A were significantly more confident in their ability to eat a health snack pre and post workout, eat a nutritious, balanced diet, eat the correct amount of calories each day, maintain a healthy weight, and keep hydrated before, during, and after practice and competition. These athletes from school B, who in general sought out more nutrition information, got more of their nutrition information from Registered Dietitians, and who were more knowledgeable about nutrition were better prepared to make nutrition decisions and felt more confident in doing so. 
Football athletes from school B were more confident in their abilities to make certain nutrition decisions; significant differences were found for each self-efficacy question. However, with men’s wrestling and women’s soccer and swimming/diving, no significant differences were found between the teams from each University regarding self-efficacy in making nutrition decisions. Again, the football team at school B has much more contact with the Sports RD than do the other teams in the study, showing that when athletes do have this type of access and interaction with a Sports RD they are much more confident in making good nutrition decisions, benefiting their athletic performance. 


\section{REFERENCES}

1. American College of Sports Medicine (ACSM), the American Dietetic Association (ADA), and Dietitians of Canada (DC). Medicine \& Science in Sports \& Exercise. 2009; 41(3): 709-731.

2. Hinton, PS, Sanford, TC, Davidson, M, Yakushko, OF, Beck, NC. Nutrient intakes and dietary behaviors of male and female collegiate athletes. International Journal of Sport Nutrition and Exercise Metabolism. 2004; 14(4), 389-405.

3. Cole, CR, Salvaterra, GF, Davis JE, et al. Evaluation of dietary practices of national collegiate athletic association division I football players. J. Strength Cond. Res. 2005; 19(3): 490-494.

4. Quatromoni, PA. Clinical observations from nutrition services in college athletics. Journal of the American Dietetic Association. 2008; 108: 689-694.

5. Volpe, SL. Micronutrient requirements for athletes. Clinics in Sports Medicine. 2007; 26: 119-130.

6. Jonnalagadda, SS, Rosenbloom, CA, Skinner, R. Dietary practices, attitudes, and physiological status of collegiate freshman football players. J. Strength Cond. Res. 2001; 15(4): 507-513.

7. Anderson, D. The impact of feedback on dietary intake and body composition of college women volleyball players over a competitive season. J. Strength Cond. Res. 2010; 24(8): 2220-2226.

8. Morse, KL, Driskell, JA. Observed sex differences in fast-food consumption and nutrition self-assessments and beliefs of college students. Nutrition Research Journal. 2009; 29: 173-179.

9. Abood, DA, Black, DR, \& Birnbaum, RD. Nutrition education intervention for college female athletes. Journal of Nutrition Education and Behavior. 2004; 36: 135-139. 


\section{CHAPTER III}

\section{CONCLUSIONS}

Past research has suggested the importance of Sports Registered Dietitians, and based on the data collected in this study, it is important that Division I Universities have a full time Sports Registered Dietitian on staff and on campus, not simply in a consulting role. Based on this study it is also important that athletes are educated on the importance of seeking out nutrition information from a reliable source, specifically Registered Dietitians. Sports Registered Dietitians at Universities should place emphasis on the importance of seeking out nutrition information and ensuring it is reliable. In this study, athletes from school B, as a whole, with access to a Registered Dietitian, received more of their information from this reliable source, placed more value on the importance of seeking out nutrition information, and in turn were more knowledgeable about general nutrition and its importance in their athletic performance.

First and foremost it is important that athletes have easy access to Registered Dietitians; when one is on-campus full-time they are more likely to seek them out for nutrition information. In this case, Sports Registered Dietitians are also more available for the coaches to educate them on proper nutrition so good nutrition practices are done as an entire team. Based on this study it is also important for Universities who have Sports Registered Dietitians to ensure each of their athletes are receiving education and counseling, not only athletes from specific teams. Based on the data collected in this study, the athletes from the three sports at school B where less focus and time are placed lacked the nutrition knowledge and self-efficacy found in the football athletes. If some 
teams are receiving a higher percentage of the effort, such as, based on this study, seemed to be occurring at school B, it is important this is identified and rectified.

Regardless of the amount of effort placed with each team, based on the data collected in this study, as a whole, athletes from Universities with full-time Sports Registered Dietitians placed more value on seeking out nutrition information, got their nutrition information from more reliable sources, had better nutrition knowledge, and identified more self-efficacy in making nutrition decisions. Therefore, it would be beneficial for each Division I University to have a Registered Dietitian, educated in Sports Nutrition, on staff, full-time, and on campus to provide counseling and education to ensure each athlete is receiving reliable nutrition information, is knowledgeable regarding proper nutrition to maximize their health and performance, and has the confidence to make proper nutrition decisions.

Overall, athletes with access to a full-time Registered Dietitian on campus full time sought out nutrition information more often and from more reliable sources. These athletes were also more knowledgeable about nutrition and also had more confidence in making certain nutrition decisions. Having a full time Sports Dietitian on campus is extremely important, but also of upmost importance is that each team be provided the same services by this Registered Dietitian. As this study showed, even athletes from the University with the full time Sports Dietitian, who had less contact with this professional, were less knowledgeable and less confident than other athletes from the same University but that had more contact with the Sports Dietitian. Each Division I University should have a Sports Dietitian on campus, full time, in order for their athletes to be properly educated and able to use nutrition to best maximize their performance and health. 


\section{LIMITATIONS}

While this study will be invaluable to the area of Sports Nutrition, will provide needed insight into the nutrition knowledge and self-efficacy of Division I athletes, and will demonstrate the importance of having a full-time Sports Dietitian on staff, some limitations do exist and should be taken into consideration.

Because of the select nature of the participants, this study is not necessarily generalizable to all athletes. Teams had to be selected which were found at each University. Also, only teams could be used if their coaches approved their athletes’ participation. This made selection of teams limited and therefore not all athletes at each University could be involved in the study.

As all assessment tools exhibit both strengths and weaknesses, the tool used in this study did as well. First, because the tool was a survey, heights and weights were selfreported, and therefore could be inaccurate. Also, there was one question that could have been clearer to the athletes. This question addressed where the athletes got their nutrition information. The term used in the survey was Registered Dietitian. It is possible many athletes from school B did not know what this term meant as the title of their Sports Registered Dietitians is “Sports Nutritionist.” It is possible they considered their Sports Nutritionist a Strength and Conditioning Coach or Athletic Trainer. If this is the case, it is possible more significant differences could have been found regarding the number of athletes from school B seeking out nutrition information from the Sports Registered Dietitian. 
Another limitation is that the researchers do not know specifically how much each athlete at school A corresponded with the Registered Dietitian. The Registered Dietitian is contracted, therefore each team utilizes this individual differently, and it is unknown which teams utilize them the most.

Finally, another limitation was the cooperation from both Athletic Departments. The staff and athletes from School A were much more compliant and cooperative with the study. Their response rate was much higher and they spent a significant amount more time going through the survey and considering ach question carefully.

\section{FUTURE RESEARCH}

As Sports Nutrition at Universities is a topic which has not been heavily researched, it is very important that more research be done to establish trends and deficits in nutrition knowledge and self-efficacy and also the importance of Sports Registered Dietitians at Universities. It would be beneficial for a mixed methods study to be done using focus groups and surveys to establish which parts of the nutrition departments were the most beneficial.

It would also be important to research how much time each Sports Registered Dietitian is spending with each of their athletes; is it the larger, more well-known teams which are receiving the majority of the education and counseling? Along with this, it may be beneficial to know how Sports Registered Dietitians currently working at Universities spend their time; do they simply do counseling and education or do they also run a Training Table or a fueling center? 
Because so many athletes identified strength and conditioning coaches as a source of nutrition information, it would be beneficial to know what type of nutrition education and knowledge strength and conditioning coaches at Division I Universities have and also how much nutrition education they are doing with their athletes. 
APPENDIX A-1

Institutional Review Board Letter of Approval 
April 12, 2011

Melissa Wallinga

Department of Nutrition and Health Sciences

8620 Lexington Ave Apt 201 Lincoln, NE 68505

Wanda Koszewski

Department of Nutrition and Health Sciences

120C LEV, UNL, 68583-0806

IRB Number: 20110411742EP

Project ID: 11742

Project Title: Assessment of Nutrient Intake and Knowledge of NCAA Student Athletes

Dear Melissa: This letter is to officially notify you of the approval of your project by the Institutional Review Board (IRB) for the Protection of Human Subjects. It is the Board's opinion that you have provided adequate safeguards for the rights and welfare of the participants in this study based on the information provided. Your proposal is in compliance with this institution's Federal Wide Assurance 00002258 and the DHHS Regulations for the Protection of Human Subjects (45 CFR 46). Your project was approved as an Expedited protocol, Category 7.

Date of EP Review: 4/12/2011

You are authorized to implement this study as of the Date of Final Approval: 04/12/2011. This approval is Valid Until: 04/11/2012.

We wish to remind you that the principal investigator is responsible for reporting to this Board any of the following events within 48 hours of the event:

* Any serious event (including on-site and off-site adverse events, injuries, side effects, deaths, or other problems) which in the opinion of the local investigator was unanticipated, involved risk to subjects or others, and was possibly related to the research procedures;

* Any serious accidental or unintentional change to the IRB-approved protocol that involves risk or has the potential to recur;

* Any publication in the literature, safety monitoring report, interim result or other finding that indicates an unexpected change to the risk/benefit ratio of the research;

* Any breach in confidentiality or compromise in data privacy related to the subject or others; or

* Any complaint of a subject that indicates an unanticipated risk or that cannot be resolved by the research staff.

For projects which continue beyond one year from the starting date, the IRB will request continuing review and update of the research project. Your study will be due for continuing review as indicated above. The investigator must also advise the Board when this study is finished or discontinued by completing the enclosed Protocol Final Report form and returning it to the Institutional Review Board. 
If you have any questions, please contact the IRB office at 472-6965.

Sincerely,

walian G. Thamento

William Thomas, Ph.D.

Chair for the IRB

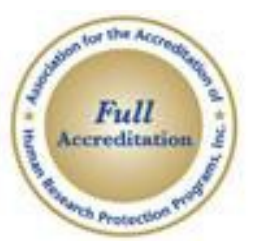


APPENDIX A-2

University of Nebraska-Lincoln, Letter of Approval 


\section{SPORTS NUTTRITION}

INTEGRITY・TRUST・RESPECT・TEAMWORK・LOYALTY

Date: March 15,2011

To: Melissa Wallinga

From: Tom Osborne (Athletic Director)

RE: Nutrient Intake and Nutrition Knowledge Study

The UNL Athletic Department is granting Melissa Wallinga permission to implement a nutrient intake and nutrition knowledge assessment on our football, wrestling,volleyball, and swimming and diving athletes to evaluate trends in the diets of the athletes,assess nutrition knowledge, and compare both variables to athletes at a University which does not have a Sports Nutrition program. We understand that the data will be kept confidential and only aggregated data will be used in reports and publications.

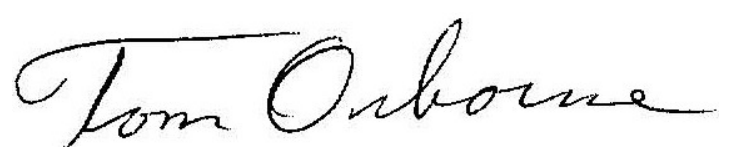

Tom Osborne

Athletic Director

\section{Inike Anther}

Mike Arthur

Head Strength and Conditioning Coach 
IRB\# 20110411742EP Date Approved: 04/12/2011

Valid Until: 04/11/2012

APPENDIX A-3

Boise State University, Letter of Approval 
Date: March 15, 2011

To: Melissa Wallinga

From: Gene Bleymaier (Athletic Director)

RE: Nutrient Intake and Nutrition Knowledge Study

The BSU Athletic Department is granting Melissa Wallinga permission to implement a nutrient intake and nutrition knowledge assessment on our football, wrestling, volleyball, and swimming and diving athletes to evaluate trends in the diets of the athletes, assess nutrition knowledge, and compare both variables to athletes at a University which has a Sports Nutrition program. We understand that the data will be kept confidential and only aggregated data will be used in reports and publications.

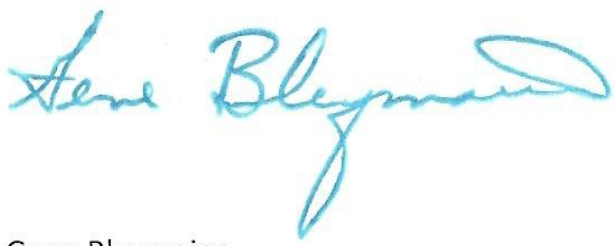

Gene Bleymaier

Athletic Director

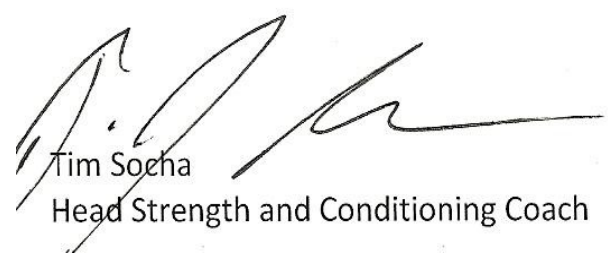


IRB\# 20110411742EP Date Approved: 04/12/2011

Valid Until: 04/11/2012

APPENDIX A-4

Informed Consent Form 


\section{NeỏaS<a

Informed Consent Form

Identification of Project: Assessing Dietary I ntake and Knowledge of NCAA Student Athletes

We would like to invite you to be a part of this study. We are asking you for your voluntary participation because you are a student athlete participating in football,wrestling, women's soccer, women's swimming and diving,men's gymnastics,or women's gymnastics at an NCAA Division I University.

Purpose of the research:

In this study we will try to learn more about the nutrient intake, nutrition knowledge, and self-efficacy of college student athletes. We will also try to learn more about the differences in these variables between a University with a Sports Nutrition program and one without. By signing this informed consent letter,you are giving the athletic department permission to share your survey and diet recall data with the investigators.

The reason for this study is that it will help a graduate student create a Master's thesis,and it is also possible this study may help provide Sports Nutritionists at Universities with data that can assist them develop better nutrition programs for their athletes. It may also provide data helpful for University Athletic Departments who are considem g developing a Sports Nutrition program. Your responses wll be strictly confidential. There will not be a way for the researchers to know which responses belong to you or to someone else. We may publish a summary of everybody"s responses or present such a summary at a scientfic meeting, but your i dentity and your responses will be completely confidential.

Procedures:

You have been informed of an opportunity to be involved in a research study and also of a one hour team meeting where you will be briefed on the purpose and methods for the study. At this meeting you will be asked to begin the first assessment for this study which is taking a survey that wil take approximately 15 minutes to complete. The second assessment you will need to complete will be in the month of June. You will be asked to complete a two-day food record and enter it into the National Cancer Institute's Automated Self-Assessment twenty-four hour recall. The recall will take you approximately 30 minutes to complete each time you enter a recall into the system. The final assessment you will need to complete will be done in the fall after you have returned to campus. This assessment will be the same as the assessment you completed in the summer; you will complete a two-day food record and enter it into the Automated Self-Assessment twenty-four hour recall. This assessment will also take you approximately 30 minutes each time you enter a recall into the system. Your participation in this study is totally voluntary.

The total time it will take to complete each assessment (survey, summer dietary assessment, and fall dietary assessment) will be approximately 2.5 hours. Including the hour mandatory meeting you wll attend your total time commtment will be 3.5 hours.

Page 1of 3 Pages

Please Initial 


\section{Risk and/or Discomfort:}

There are no known risks or discomforts associated with this research.

Benefits:

The benefits of this project are that the results wil help Sports Nutritionits at Universities understand the general trends in nutrition knowledge, self-efficacy, and diets of athletes, and what areas college athletes are doing well in as well as areas that need improvement. Additionally, the need for Sports Nutritionists at al NCAA Diviso $n$ I Universi ti es will be identified. If you request your results using your assigned ID number they will be privately shared with you after you have completed both assessments. To request your results after both data collections have been completed,you can contact either the primary or secondary investi gator by e-mail. Please reference the bottom of page 3 of this form for this information.

Confidentiality:

Any information obtained during this study which could identify you will be kept strictly confidential. The data will be stored in a locked cabinet and will only be seen by the $\mathbf{i}$ nvestigator during the study. The information obtained throughout this study may be published in scientfic journals or presented at scientific meetings but the data will only be reported as aggregated data.

Opportunity to Ask Questions:

You may ask any questions concerning this research and have those questions answers prior to agreeing to participate in or throughout the study. You may also call the investigator at any time at

402-472-7966. Please contact the investigator:

- If you would Iike to voi ce concerns or complaints about the research.

- In the event of a research related injury

Please contact the University of Nebraska-Lincoln Institutional Revi ew Board at 4402) 472-6965 for the following reasons:

- You would like to talk with someone other than the research staff to obtain answers to questions about your rights as a research participant

- To voi ce concerns or complaints about the research

- To provide input concerning the research process

- In the event the study staff could not be reached

\section{Freedom to Withdraw:}

Your participation in this study is totally voluntary. You can refuse to participate or withdraw at any time without harming your relationship with the researchers, Boi se State University, the University of Nebraska-Lincoln or in any other way receive a penalty or loss of benefits to which you are otherwise entitled.

Page 2 of 3 Pages

Please Initial 


\section{Consent, Right to Receive a Copy}

You are voluntarily making a decision whether or not to participate in this research study. Your signature certifies that you have decided to parti cipate having read and understood the informati on presented. You will be given a copy of this consent form to keep.

If you have any questions at any time, please ask one of the researchers.

Signature of Subject,Date

Signature of Investigator, Date

INVESTIGATOR

Melissa Wallinga,Graduate Student/Primary Investigator

Wanda M. Koszewski PhD, RD/Secondary Investigator Josh

Hingst,MS, RD, SCCC, LMNT/Co-Investigator

Lindsey Remmers,MS, RD,CSSD, LMNT/Co-Investigator

Phone: 402-472-6368

Phone: $402-472-7966$

Phone: $402-472-4618$

Phone: 402-472-2778

Page 3 of 3 Pages 
APPENDIX A-5

Athlete Survey 


\section{Assessment of Nutrient Intake and Knowledge of NCAA Student Athletes}

The purpose of this research study is to assess the nutrient intake and nutrition knowledge of athletes at two NCAA Division I Universities. All information obtained throughout this study will be kept strictly confidential. Please read each of the following questions carefully and check the choice that is most applicable to you. Thank you for your participation in this study.

ID

Height

ft

in

Weight

Ibs

E-mail

Age

Gender

Male

Female

Major

Class Year

Freshman

Sophomore

Junior

Senior

Senior +

Race/Ethnicity

African American

White

Asian

Hispanic

Native American

Other (please specify)

Sport

Football

Wrestling

Soccer

Swimming/Diving

Men's Gymnastics

Women's Gymnastics

Position (if applicable) 
1. Do you have access to nutrition counseling?

Yes__ No ___ I don't know

2. Do you actively seek out or read nutrition information?

Yes__ No ___ I don't know

2a. If you do, from where? (check all that apply)

\begin{tabular}{ll} 
Teammates & Magazines \\
\cline { 2 - 2 } Family & Doctor \\
Strength and Conditioning Coach & Supplement Store \\
Athletic Trainer & Registered Dietitian \\
\hline Internet & \\
\hline Other (please list) &
\end{tabular}

$2 b$. If you don't, why not? (check all that apply)

No time

It is not a major concern

You already have enough nutrition knowledge

Other (please list)

3. Do you read the nutrition facts label when selecting a food item to eat?

Yes__ No___ don't know what a nutrition facts label is

3a. If you do, what do you specifically look at the nutrition facts label for? (check all that apply)

$\begin{array}{ll}\text { Calories } & \text { Sodium } \\ \text { Fat grams } & \text { Fiber } \\ \text { Saturated fat } & \text { Protein } \\ \text { Monounsaturated Fat } & \text { Carbohydrates (sugar, etc.) } \\ \text { Polyunsaturated Fat } & \text { Calcium, iron, vitamins } \\ \text { Other (please list) } & -\end{array}$

3b. If you do not, what are the reasons? (check all that apply)

It is too time consuming

I don't know what to look for on the label

It is not important

Other (please list)

4. Having a nutritious diet will improve my athletic performance.

Yes__ No__ I don't know

5. I am aware of how many calories I need to consume every day to promote my best athletic performance.

Yes ___ No _ I don't know

6. Having a Sports Nutritionist at my University is or would be helpful to me as an athlete.

Yes__ No ___ d don't know

7. Carbohydrates and fats are the main sources of energy for the muscles.

Yes___ No__ I don't know

8. Protein is the primary source of energy for the muscles.

Yes__ No ___ I don't know 
9. Protein supplements are needed in addition to food for muscle growth and development.
Yes
No I don't know

10. The vast majority of supplements sold to the general public have been tested for effectiveness or safety.

Yes _ No N _ I don't know

11. Consuming fruits and vegetables every day is important in order to get necessary vitamins and minerals.

Yes __ No ___ I don't know

12. High-fat foods should be reduced in my diet.

Yes__ No _ I I don't know

13. Vitamin and mineral supplements provide energy to my body.

Yes _ No_ _ I don't know

14. My coaches have encouraged me to either lose or gain weight.
Yes
No I don't know

15. It is recommended to consume sports drinks during practices and competitions lasting longer than 1 hour.

Yes __ No _ _ I don't know

16. Sports drinks like Gatorade and Powerade are better than drinking water and should be consumed all throughout the day.

Yes No I don't know

17. During 2-a-days or heavy practice days I should eat more calories.

Yes

No I don't know

18. When I am inactive my calorie needs do not change. Yes__ No ___ d don't know

19. Eating within 45 minutes of a workout is important. Yes__ No _ I I don't know

20. Milk is a good source of Calcium and Vitamin D.

Yes__ No _ I don't know

21. Whole grain breads are a good source of fiber.

Yes_ No I I don't know

22. A turkey breast is a good source of lean protein.

Yes__ No ___ don't know 
Use a number from 1 to 10 on the following scale to tell how certain you are that you can do the following

things all or most of the time:

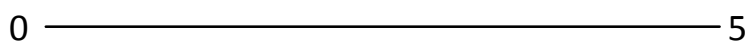

10

Certain I CAN NOT Somewhat certain I CAN

Certain I CAN

How certain are you that you can...

How certain (0-10)

Eat a healthy snack pre-and post-workout

Eat a nutritious, balanced diet

Eat the correct amount of calories each day

Maintain a healthy weight with diet and exercise

Keep hydrated before, during, and after practice and

competition 
APPENDIX A-6

Script for initial recruitment meeting 


\section{Spring Meeting Script}

Starting this spring and continuing through next fall we are conducting a study using survey and dietary recall data from student athletes at your University. We are asking you to participate in this study. You will be asked to complete a survey and two-two day dietary recalls. Your participation in this research is totally voluntarily.

The purpose of this study is to collect dietary intake, nutrition knowledge, and self-efficacy data from athletes at two NCAA Division I Universities and to examine differences of the athletes who have access to a nutrition program and those who do not. Results from this study will help to reveal the need for interventions in certain areas of athletes' diets and also the need for a Sports Nutrition program at all Division I Universities.

The first portion of this study will be completed today. It is a survey which should take approximately 15 minutes to complete.

The second portion of this study will be completed during the month of June and you will be able to complete it from home or from campus. This portion involves you completing a two-day food record. You will complete a dietary recall for one weekday (Monday through Thursday) and one weekend-day (Friday through Sunday) using the paper form provided for you. You will then enter this data into the National Cancer Institute's Automated Self Assessment twenty-four hour recall (ASA24). This site is encrypted and does not store the IP address of the computer you are using. Therefore, it is completely confidential and you will only be identified throughout the study by the ID number randomly assigned to you. I will contact you by e-mail closer to the date that ASA24 will open with your ID and password to log onto the site. I will also send out reminders when the site opens and when it is going to close. You will have a month to complete this portion.

The third portion of this study is identical to the second portion only it will be completed in the fall. You will again complete a two-day dietary recall and enter this data into ASA24. I will again contact you by e-mail informing you when the site has been opened and again when it will be closing. I am now going to demonstrate how to use ASA24.

\section{[Demonstration]}

All of the data will be used to identify trends and areas of athletes diets, nutrition knowledge, and self efficacy which are sufficient and also areas which need improvement. Also, a comparison of the data between the University with a Sports Nutrition Department and the University without one will be done.

After all of the data has been collected, each of you will have the option of being given an assessment of the dietary recall you completed. If you choose to request your results using your randomly assigned ID number you will be able to see your caloric intake, your nutrient intake, and also how your diet compares with recommendations.

[Hand out survey with attached informed consent form] 
Please read and sign the informed-consent form that has been passed out to you. After you have initialed the first two pages and signed the third page, please complete the survey which is attached. When you have completed the informed-consent form and the survey please hand it to [insert name of athletic department staff member in attendance]. The second copy of the informed-consent form is for you to keep for your records.

Also, before you leave, please sign in the sheet that is coming around so we have a second copy of your e-mail address.

If you have any questions I will be happy to answer them, or you can also contact Dr. Wanda Koszewski whose information is on the informed consent. Thank you for your participation in this study. 